UNIVERSITY OF GOTHENBURG

SCHOOL OF BUSINESS, ECONOMICS AND LAW

WORKING PAPERS IN ECONOMICS

No 578

\title{
Optimal Expectations and \\ the Welfare Cost of Climate Variability
}

Yonas Alem and Jonathan Colmer

December 2013

ISSN 1403-2473 (print)

ISSN 1403-2465 (online)

Department of Economics

School of Business, Economics and Law at University of Gothenburg

Vasagatan 1, PO Box 640, SE 40530 Göteborg, Sweden

+4631786 0000, +46 317861326 (fax)

www.handels.gu.se info@handels.gu.se 


\title{
Optimal Expectations AND the WeLFARE Cost of Climate Variability*
}

\author{
Yonas Alem \\ Jonathan Colmer \\ University of Gothenburg \& UC Berkeley London School of Economics
}

\begin{abstract}
Uncertainty about the future is an important determinant of well-being, especially in developing countries where financial markets and other market failures result in ineffective insurance mechanisms. However, separating the effects of future uncertainty from realised events, and then measuring its impact on utility presents a number of empirical challenges. This paper addresses these issues and shows that increased climate variability (a proxy for future income uncertainty) reduces farmers' subjective well-being, consistent with the theory of optimal expectations (Brunnermeier $\&$ Parker, 2005), using panel data from rural Ethiopia and a new data set containing daily atmospheric parameters. The magnitude of our result indicates that a one standard deviation (7\%) increase in climate variability has an equivalent effect on life satisfaction to a two standard deviation (1-2\%) decrease in consumption. This effect is one of the largest determinants of life satisfaction in rural Ethiopia.
\end{abstract}

(JEL: C25, D60, I31.)

\footnotetext{
*First draft: June 2012. Alem - Department of Economics, University of Gothenburg, Sweden and Department of Agricultural and Resource Economics, UC Berkeley, USA. E-mail: yonas.alem@economics.gu.se. Colmer - The Grantham Research Institute and London School of Economics, UK. E-mail: j.m.colmer@lse.ac.uk. We are grateful to Allen Blackman, Jeffery Bookwalter, Gharad Bryan, Douglas Dalenberg, Paul Dolan, John Feddersen, Greer Gosnell, Cameron Hepburn, Derek Kellenberg, Peter Martinsson, Kyle Meng, Rob Metcalfe, Eric Neumayer, Jonathan Parker, Hendrik Wolff and seminar participants at the EfD 6th Annual Meeting, EAERE, the University of Oxford, London School of Economics, University of Montana, and Resources for the Future for helpful thoughts, comments and discussions. The first author would like to thank the Swedish International Development Agency (Sida) through the Environment for Development Initiative (EfD) at the University of Gothenburg, and the Swedish Research Council Formas through the Human Cooperation to Manage Natural Resources (COMMONS) programme for financial support. Part of this research was done while Alem was a Visiting Scholar at the Department of Agricultural and Resource Economics, University of California Berkeley. The second author would like to thank the ESRC Centre for Climate Change Economics and Policy and the Grantham Foundation for financial support. The data used in this article were collected by the University of Addis Ababa, the International Food Policy Research Institute (IFPRI), and the Centre for the Study of African Economies (CSAE). Funding for the ERHS survey was provided by the Economic and Social Research Council (ESRC), the Swedish International Development Agency (SIDA) and the United States Agency for International Development (USAID).All errors and omissions are our own.
} 
"Climate is what you expect, weather is what you get."

- John M. Wallace, Professor of Atmospheric Science -

\section{Introduction}

This paper examines the impact of future income uncertainty on experienced utility. Using two rounds of individual-level panel data, combined with a new data set of village-level meteorological data, we exploit exogenous variation in future income uncertainty, proxied by climate variability, to explore the impact on the self-reported life satisfaction of smallholder farmers in Ethiopia - one of the least developed countries in Africa, characterised by its high vulnerability to climate change and variability.

The motivation of this paper is two-fold. First, we want to understand how uncertainty affects welfare, a question that poses serious difficulties relating to measurement and identification. We provide supporting evidence for the theory of optimal expectations presented by Brunnermeier \& Parker (2005). There is substantial evidence to suggest that individuals perform poorly in assessing probabilities and consequently overestimate the likelihood of success (Weinstein, 1980; Alpert \& Raiffa, 1982; Buehler et al. 1994; Rabin \& Schrag, 1999; Brunnermeier \& Parker, 2005). In line with this evidence and in contrast to standard neoclassical models of expectations, we argue that our results can be better explained by a model of utility and behaviour in which beliefs about future states of the world impact utility directly (Brunnermeier \& Parker, 2002; 2005; Kozegi, 2003; 2006; Caplin \& Leahy, 2004; 2005; Gollier, 2005; Oster, Shoulson, \& Dorsey, forthcoming). In section 3, we present a brief model of optimal expectations, based on Brunnermeier \& Parker (2005), that provides a useful framework for interpreting the results in this paper, and gives structure to our identification strategy.

Secondly, we want to better understand climatic influence on economic outcomes. Recent evidence suggests that global climate change is likely to increase the incidence of environmental disasters, as well as the variability of 
rainfall, temperature, and other atmospheric parameters (IPCC, 2007; 2012), which in turn increases uncertainty about future income, especially in developing countries.

While some of the costs related to weather and climate are relatively simple to measure, such as impacts on agriculture, health, and labour-market outcomes, other aspects are harder to measure, such as the experienced utility effects of increased risk and uncertainty associated with higher variability in weather and climate. It is this aspect of climatic influence, currently absent from the literature, that we aim to capture here: the role that ex ante beliefs about the likelihood of future climatic events plays in decision-making and determining well-being. In this respect, climate variability is likely to affect welfare predominantly through the psychological impact of risk and uncertainty (van den Bos, Hartevald \& Stoop, 2009; Hare, Camerer \& Rangel, 2009; Delgado \& Porcellie, 2009; Doherty \& Clayton, 2011). So far, the majority of the literature on climatic influence has focused on ex post impacts (Deschênes \& Greenstone, 2007; 2012; Guiteras, 2009; Schlenker \& Roberts, 2009; Burgess et al., 2012; Dell, Jones, \& Olken, 2012; Fisher et al. 2012; Barreca et al., 2013). To the best of our knowledge, there is only one other paper that has explored the ex ante considerations related to climate change. Colmer (2013) examines the impact of future income uncertainty (proxied by climate variability) on household decision-making in the context of child labour and human capital accumulation.

Our results show that a one standard deviation (7\%) increase in climate variability - defined as the coefficient of variation in rainfall over the previous 5-10 years - has an equivalent effect on life satisfaction to a two standard deviation (1-2\%) decrease in real per capita consumption. We show this to be one of the largest determinants of subjective well-being (SWB) in rural Ethiopia. In a wider context, our results are consistent with the literature, which demonstrates that SWB is correlated with stress (Diener \& Chan, 2011) and weather shocks (Carroll et al., 2009). However, we also show that the magnitude of this effect on the well-being of smallholder farmers in rural Ethiopia is unprecedented, and identify a separate channel - uncertainty about future states of 
the world - through which climate affects well-being. This result is consistent with the theory of optimal expectations, in which beliefs about the state of the world impact utility directly (Brunnermeier \& Parker, 2005). Crucially, we disentangle the effects of climate variability from weather by controlling for rainfall and temperature on the day that each household was surveyed, as well as controlling for realised weather shocks. ${ }^{1}$

Our result can be interpreted as a causal effect, conditional on the assumption that our measure of climate variability has an impact on experienced utility only through uncertainty about future states of the world. In order to support this assumption we control for past rainfall shocks, current consumption, contemporaneous weather, and unobserved individual heterogeneity, an important determinant of SWB. ${ }^{2}$

We also present the results from a series of placebo and robustness tests used to disentangle the effect from other confounding factors and provide supporting evidence for the main identification assumption. ${ }^{3}$

First, we observe that, while rainfall shocks impact current consumption, climate variability has no effect, indicating a separation between ex ante beliefs about future shocks, and the ex post impact of shocks.

Secondly, we show that the effect is driven by variation in the short rainy season (the Belg season), the season in which the annual planting decisions take place. We also show that the dry season has no effect on life satisfaction,

\footnotetext{
${ }^{1}$ It is important to distinguish between weather, defined as atmospheric conditions over a short period of time, and climate, defined as the behaviour of the atmosphere over a longer period. By looking at the variability of rainfall over a longer period of time, more extended inter-annual patterns of climate variability are revealed that cannot be seen over the period of one year.

${ }^{2}$ Unobserved individual heterogeneity is a major omitted-variable bias problem in research on SWB. Almost all previous studies on SWB in Africa use cross-sectional data, which makes it difficult to control for unobserved individual heterogeneity, and is likely to affect the consistency of estimated parameters. Until now, the only exception has been the study by Alem \& Köhlin (2012), who investigate the determinants of SWB in urban Ethiopia using three rounds of panel data spanning a decade. Controlling for such unobservables is key to understanding the determinants of SWB (Argyle, 1999; Diener \& Lucas, 1999; Ferrer-i-Carbonell \& Frijters, 2004); Feddersen et al. (2012).

${ }^{3}$ Appendix C, provides a number of more mechanical robustness tests, which help support the statistical and economic significance of the results, but matter less for supporting the identification assumptions made.
} 
as one would expect if the effects of climate variability on life satisfaction operate in any way through income channels (through uncertainty or income shocks).

Thirdly, using a separate panel data set, we find no effect of climate variability on urban households, indicating that climate variability is not a major determinant of future income uncertainty in areas that are not dependent on agriculture for income.

Finally, we examine alternative measures of the dependent variable to exploit the difference between evaluative measures of SWB, such as life satisfaction, and contemporaneous measures of SWB, such as happiness. We find a surprisingly similar impact of climate variability on the Cantril ladder scale (an alternative evaluative measure), and find no effect on happiness, consistent with the idea that climate variability impacts utility through future income uncertainty and not contemporaneous effects. In line with this reasoning, we find that increased temperature on the day of the survey has a positive contemporaneous effect on happiness, but not on the evaluative measures.

The paper has the following structure: section 2 presents a brief literature review; section 3 presents the theoretical framework; section 4 presents the data and the empirical strategy; section 5 presents our main results; section 6 presents supporting evidence and robustness tests; the final section presents our conclusions.

\section{Background}

The past decade has seen rapid growth in research on, and policy interest in, SWB. In addition to "objective" measures of welfare, most commonly GDP, subjective measures of welfare are increasingly being used to elicit measures of experienced utility (Kahneman et al., 1997; Frey \& Stutzer, 2002; Kahneman \& Krueger., 2006; Dolan \& Kahneman, 2008), to value non-market goods (Welsch, 2002; 2006; Rehdanz \& Maddison, 2005; 2008; Carroll et al., 2009; Frey et al., 2007; Metcalfe et al., 2011; Feddersen et al., 2012; Levinson, 2012) and to evaluate government policy (Gruber \& Mullainathan, 2005; Diener et 
al., 2009; Dolan et al., 2011; Boarini et al., 2012; Levinson, 2013). Wellbeing is a broad measure of welfare that encompasses all aspects of the human experience. Researchers in this expanding field of economics use subjective measures of well-being to analyse and evaluate the impact of economic and non-economic factors on people's experienced utility.

Much of the existing evidence on the determinants of SWB come from studies undertaken in developed countries with similarities, on the impact of the different correlates of SWB. ${ }^{4}$ Several studies indicate that income has a positive effect on SWB, yet there is evidence to suggest that their relationship exhibits diminishing marginal returns, in part due to the roles that relative income and social position play, which can affect SWB negatively. ${ }^{5}$ With its robustly documented U-shaped impact, age has been found to be one important determinant of SWB, where the lowest level of SWB experienced is in middle age (Blanchflower \& Oswald, 2004; Ferrer-i-Carbonell \& Gowdy, 2007) and women have been found to report a higher level of SWB than men (Alesina, et al. 2004). Studies also document a positive impact of being in a relationship on SWB (e.g. Frey \& Stutzer, 2002; Dolan \& Kahneman, 2008; MacKerron, 2011). The levels of both physical and psychological health have also been found to be strong determinants of SWB (e.g., Dolan \& Kahneman, 2008).

In recent years, researchers have started to use SWB indicators to investigate the impact of a number of environmental and climatic variables. Most recently, Devoto et al. (2012) ran a randomised experiment in Tangier, Morocco, facilitating the connection of piped water to a random sample of households. While households did not experience any health benefits from a direct connection, and the water bill in newly connected households roughly doubled, households reported increased life satisfaction and other measures of well-being

\footnotetext{
${ }^{4}$ Studies on SWB conducted in developing and emerging countries include Ravallion \& Lokshin (2005) on Russia; Kingdon \& Knight (2006) and Bookwalter \& Dalenberg (2004, 2010) on South Africa; Graham \& Pettinato (2001; 2002) on Peru and Russia; Appleton \& Song (2008), Qian \& Smyth (2008) and Knight \& Gunatilaka (2010) on urban China; Knight et al. (2009) on rural China; Davis \& Hinks $(2008,2010)$ on Malawi; and Alem \& Martinsson (2011) and Alem \& Köhlin (2012) in urban Ethiopia.

${ }^{5}$ Clark et al. (2007) undertake an extensive survey of the literature on the relationship between income and happiness.
} 
associated with access to clean water, indicating welfare improvements even in the absence of health or income gains.

Using a set of cross-country and panel data from happiness surveys in combination with data on income and air pollution from European countries, Welsch $(2002 ; 2006)$ investigates the relationship between pollution of the environment and SWB of citizens. The studies find that air pollution impacts SWB significantly and is one explanatory factor of observed differences in reported SWB across countries and over time. Similarly, using life satisfaction data from the German Socio-Economic Panel survey in combination with county-level pollution (sulphur dioxide) data, Luechinger (2009) documents that higher concentration levels affect SWB negatively and significantly. Ferreira \& Moro (2010) document a similar negative impact of air pollution captured by the concentration of $P M_{10}$ on reported level of happiness in Ireland.

The impact of climatic variables (amount of rainfall and temperature) on SWB has been investigated by Rehdanz \& Maddison (2005), who document significant impacts on country-wide self-reported levels of happiness. More recently, Carroll et al. (2009) examine the impact of a period of drought in Australia on life satisfaction, finding a detrimental impact equivalent to an annual reduction in income of $\mathrm{A} \$ 18,000$ (US\$14,500). ${ }^{6}$ However, many of these studies use cross-sectional data and so are unable to control for individual unobserved heterogeneity. However, the most recent paper in this literature by Feddersen et al. (2012) examines the differential impacts of weather and climate change on SWB in Australia, controlling for unobserved individual heterogeneity. They examine the impact of short-term weather fluctuations and long-term climate on standard SWB response variables. They find that day-to-day weather variation impacts life satisfaction by a similar magnitude to acquiring a mild disability, however, the effect of long-term climate on life satisfaction disappears with the inclusion of individual fixed effects, suggesting that unobserved individual-specific factors are responsible for the direct link between climate and life satisfaction in the studies focussed on average climate.

\footnotetext{
${ }^{6}$ Welsch \& Kuehling (2009) and Ferreira et al. (2012) undertake comprehensive overviews of research in the area of environmental quality and SWB.
} 
While these studies have focussed on long-run climate and weather shocks - the ex post realisations of weather and climate - we are unaware of any study that has looked at the effect climate variability - an ex ante consideration -, nor the impact of future income uncertainty on well-being. Given the importance of risk and uncertainty in developing countries, and the role that climate change is likely to have on development, exploring the interaction between these issues is an important area of research.

Despite a large number of papers examining the determinants of SWB, only a small number of studies provide causal estimates of an event or experience on SWB. This is because SWB studies rarely have, or make use of, exogenous variation in their variable of interest. By using fixed effects to control for individual heterogeneity, controlling for potential confounding factors, and teasing out the mechanism by which we expect climate variability to be important namely, through the impact of increased stress through uncertainty about future income -, we attempt to provide supporting evidence for a causal estimate of climate variability on the SWB of smallholder farmers in rural Ethiopia.

\section{The Optimal Expectations Framework}

Based on the work by Brunnermeier \& Parker (2005) we construct a model in which farmers care about their expectations of the future (anticipatory utility) in addition to their present consumption, that is, all farmers care about current utility and expected future utility. While all forward-looking farmers who care about expected future utility will make investments to maximise future utility, such farmers will have higher current utility if they are optimistic about the future. In the context of this paper, farmers living in areas with higher climate variability will have higher subjective probabilities about the likelihood of a negative income shock being realised in the next period, and so will have lower current utility. By contrast, farmers living in areas with lower climate variability will have higher subjective probabilities that a negative income shock will not occur, and so will have higher current utility. 


\subsection{Utility Maximization Given Beliefs}

Consider a world in which uncertainty about future income can be described by a binary state $s_{t} \in\{0,1\}$, where $s_{t}=1$ indicates that the farmer is going to experience a negative income shock and $s_{t}=0$ indicates that they will not. Let $p\left(s_{t} \mid \underline{\mathrm{s}}_{t-1}\right)$ denote the true probability that state $s_{t} \in\{0,1\}$ is realised following state history $\underline{\mathrm{s}}_{t-1}=\left(s_{1}, s_{2}, \ldots, s_{t-1}\right) \in\{0,1\}$. We depart from the standard neoclassical model in so far as agents are endowed with subjective probabilities that may not coincide with the true state. Conditional and unconditional subjective probabilities are denoted $\hat{p}\left(s_{t} \mid \underline{\mathbf{s}}_{t-1}\right)$ and $\hat{p}\left(s_{t}\right)$ respectively.

At time $t$, the farmer receives some level of income which is consumed, $c_{t}$. For tractability, we assume there are no savings, so income is equal to consumption. In addition, the farmer chooses some binary risk management action, $\alpha_{t} \in\{0,1\}$, used to mitigate income shocks, based on their beliefs about the likelihood of future income shocks to maximise utility,

$$
\hat{\mathbb{E}}\left[U\left(c_{t}, \alpha_{t}\right) \mid \underline{\mathbf{S}}_{t}\right]
$$

,where $U(\cdot)$ is strictly increasing and strictly quasi-concave, and $\hat{\mathbb{E}}$ is the subjective expectations operator associated with $\hat{p}$, which depends on information available at time, $t$.

The farmer maximises utility of consumption subject to their budget constraint:

$$
\begin{aligned}
c_{t+1} & =f\left(c_{t}, \alpha_{t}, s_{t+1}\right), \\
g\left(c_{T+1}\right) & \geq 0 \text { given } c_{0}
\end{aligned}
$$

where $f(\cdot)$ provides the evolution of income is continuous and differentiable in c and $\alpha$, and $g(\cdot)$ gives the endpoint condition. The optimal choice of action is denoted $\alpha^{*}\left(\underline{\mathrm{s}}_{t}, \hat{p}\right)$ and the induced consumption as $c^{*}\left(\underline{\mathrm{s}}_{t}, \hat{p}\right)$.

The utility of the farmer depends on expected future utility or anticipated utility, such that the subjective conditional belief has a direct impact on utility. 
To clarify this further, we consider time-separable utility flows with exponential discounting.

$$
\hat{\mathbb{E}}\left[U\left(c_{t}\right) \mid \underline{\mathbf{S}}_{t}\right]=\beta^{t-1}\left(\sum_{\tau=1}^{t-1} \beta^{\tau} u\left(c_{t-\tau}, \alpha_{t-\tau}\right)+u\left(c_{t}, \alpha_{t}\right)+\hat{\mathbb{E}}\left[\sum_{\tau}^{T-t} \beta^{\tau} u\left(c_{t+\tau}, \alpha_{t+\tau}\right) \mid \underline{\mathbf{S}}_{t}\right]\right)
$$

In this situation, utility at time $t$ is the sum of memory utility from past consumption, utility from current consumption, and anticipatory utility from future consumption. Empirically, we identify these factors by controlling for past weather shocks (memory utility), real per capita consumption and contemporaneous weather (current consumption), and climate variability (anticipatory utility).

\subsection{Optimal beliefs}

The subjective beliefs of farmers are a complete set of conditional probabilities following any history of events, $\hat{p}\left(s_{t} \mid \underline{s}_{t-1}\right)$. That is, the subjective probability that a shock will occur depends on the history of shocks in the past. In this way, locations which have a more variable climate may be more likely to have a shock in the future.

Following Brunnermeier \& Parker (2005), optimal expectations are the subjective probabilities that maximise the farmer's lifetime happiness and are defined as the expected time-average of the farmer's utility.

Definition 1 Optimal expectations (OE) are a set of subjective probabilities $\hat{p}^{O E}\left(s_{t} \mid \underline{s}_{t-1}\right)$ that maximise well-being

$$
\mathbb{W}=\mathbb{E}\left[\frac{1}{T} \sum_{t=1}^{T} \hat{\mathbb{E}}\left[U\left(c_{1}^{*}, \ldots, c_{T}^{*}, \alpha_{1}, \ldots, \alpha_{T} \mid \underline{s}_{t}\right)\right]\right]
$$

One of the benefits of this model is that if farmers have rational expectations (i.e. $\alpha=s$ ), then the well-being and utility derived from the actions that 
farmer's will coincide. In this case, utility in time t only depends on present actions, i.e., memory utility and anticipatory utility does not enter into the utility function. This could be the case, for example, if an exact weather forecast or insurance is available. However, if subjective probabilities differ from the true probability that a shock will occur then there will be a wedge between well-being and the farmer's utility, in this case memory utility and anticipatory utility enter into the utility function as in equation 4.

\section{Data and Empirical Strategy}

\subsection{Data}

The analysis conducted in this paper uses two rounds of a panel data set - the Ethiopian Rural Household Survey (ERHS) - that covers households from 15 villages in rural Ethiopia?. The ERHS was conducted by Addis Ababa University in collaboration with the Center for the Study of African Economies (CSAE) at the University of Oxford and the International Food Policy Research Institute (IFPRI) in seven rounds between 1994 and 2009. The sampling was constructed carefully to represent the major agro-ecological zones of Ethiopia. Households from six villages that were affected by drought in central and southern Ethiopia were surveyed for the first time in 1989. In 1994, the sample was expanded to cover 15 peasant associations ${ }^{8}$ across the major regions of Ethiopia (Tigray, Amhara, Oromia, and Southern Nations Nationalities and people's region), representing 1477 households. Further rounds were completed in 1995, 1997, 1999, 2004 and 2009. The additional villages incorporated in the sampling were chosen to account for the diversity in the farming systems throughout the country. Stratified random sampling was used within each village based on the gender of household heads.

This paper makes use of the final two rounds, 2004 and 2009, as only these years contain questions on SWB. This is sufficient to control for unobserved

\footnotetext{
${ }^{7}$ See figure 3 in appendix A for the location of these villages.

${ }^{8} \mathrm{~A}$ peasant association is the lowest administrative unit in Ethiopia and normally consists of several villages.
} 
heterogeneity. Attrition of the panel has been low at 1-2 percent of households per year (Dercon \& Hoddinott, 2009). In addition to a specific module on SWB, the data set contains detailed information on individual and household characteristics, assets, expenditures, consumption, health, agricultural production, and information related to input use.

In addition to the household survey data, daily, seasonal and annual rainfall data has been constructed from 6-hourly precipitation reanalysis data at the village level from the ERA-Interim data archive supplied by the European Centre for Medium-Term Weather Forecasting (ECMWF). ${ }^{9}$ Previous studies have relied on the use of meteorological data provided by the Ethiopian meteorological service and the number of missing observations is a concern. This is exacerbated by the serious decline in the past few decades in the number of weather stations around the world that are reporting. Lorenz \& Kuntsman (2012) show that, since 1990, the number of reporting weather stations in Africa has fallen from around 3,500 to around 500. With 54 countries in the continent, this results in an average of fewer than 10 weather stations per country. Looking at publicly available data, the number of stations in Ethiopia included by the National Oceanic and Atmospheric Administration's (NOAA) National Climatic Data Centre (NCDC) is 18; however, if we were to apply a selection rule that required observations for 365 days, this would yield a database with zero observations. For the two years for which we have economic data (2004 and 2009), weather station data is available for 50 days in Addis Ababa in 2004 and is available for all 18 stations for an average of 200 days (minimum of 67 days, maximum of 276 days) in 2009. This is likely to result in a huge increase in measurement error when this data is used to interpolate across the 63 zones and 529 woredas (districts) reported in 2008. If this measurement error is classical, i.e., uncorrelated with the actual level of rainfall measured, then our estimates of the effect of these variables will be biased towards zero. However, given the sparse density of stations across ethiopia (an average of 0.03 stations per woreda), the placement of stations is likely to be correlated with agricultural output, i.e. weather stations are placed in

\footnotetext{
${ }^{9}$ See Dee et al. (2011) for a detailed discussion of the ERA-Interim data.
} 
more agriculturally productive areas, where the need for weather information is higher. As a result, we might expect that estimates using weather stations are systematically upward biased. For these reasons, the use of remote-sensing data on a uniform grid has great value in areas with low station density.

The ERA-Interim reanalysis data archive provides 6-hourly measurements of precipitation, temperature (min., max., and mean), wind speed and wind direction, relative humidity, cloud cover (a proxy for solar reflectance), and many other atmospheric parameters, from January 11979 until the present day, on a global grid of quadrilateral cells defined by parallels and meridians at a resolution of $0.75 \times 0.75$ degrees (equivalent to $83 \mathrm{~km} \times 83 \mathrm{~km}$ at the equator). ${ }^{10}$ Reanalysis data is constructed through a process whereby climate scientists use available observations as inputs into climate models to produce a physically consistent record of atmospheric parameters over time (Auffhammer et al., 2013). This results in an estimate of the climate system that is separated uniformly across a grid, making it more uniform in quality and realism than observations alone, and one that is closer to the state of existence than any model would provide alone. This provides a consistent measure of atmospheric parameters over time and space. This type of data is increasingly being used by economists (see Guiteras, 2009; Schlenker \& Lobell, 2010; Hsiang et al. 2011; Burgess et al., 2011; Kudumatsu, 2012), as they fill in the gap in developing countries, where the collection of consistent weather data is lower down the priority list in governmental budgets.

By combining the ERHS data set with the ERA-interim data, we create a unique panel allowing for microeconomic analysis of weather and climate in Ethiopia.

The outcome variable of interest from the economic data is a measure of overall life satisfaction asked to the head and spouse of the household. It is constructed using responses to a single question, scored on a seven-point scale ranging from one to seven. The variable is constructed using responses related to the level of agreement with the following statement as the dependent

\footnotetext{
${ }^{10}$ To convert degrees to $\mathrm{km}$, multiply 83 by the cosine of the latitude, e.g, at 40 degrees latitude $0.75 \times 0.75$ cells are $83 \times \cos (40)=63.5 \mathrm{~km} \times 63.5 \mathrm{~km}$.
} 
variable: "I am satisfied with my life." A score of one is described as "Very Dissatisfied" and a score of seven is described as "Very Satisfied". This is very similar to the standard questions used in cross-country surveys, such as the World Values Survey and the Eurobaromoter Survey. Later in the paper, we demonstrate the robustness of our results to alternative measures of SWB.

\subsection{Variables and Descriptive Statistics}

Table 1 presents descriptive statistics of the key dependent variable - the reported level of life satisfaction - for the analysed period. Average reported level of life satisfaction in rural Ethiopia was 2.93 in 2004 but increased to 3.09 in 2009. In the sample, about 40 percent of the respondents reported to be dissatisfied in 2004, but the figure declined to 34 percent in 2009. The proportion of respondents that were very satisfied was around 2 percent in 2004, but the figure increased to just over 6 percent in 2009. Overall, one notices that there has been a considerable rise in the average reported level of life satisfaction in rural Ethiopia during the period in which the country experienced rapid economic growth.

We categorize our explanatory variables into climatic, individual (respondent) and household variables.

Rainfall at each village is calculated by taking all data points within $100 \mathrm{~km}$ of the village, which is then interpolated through a process of inverse distance weighting. Taking the annual measure of rainfall at each village we calculate the coefficient of variation for rainfall $(\mathrm{CV})$, measured as the standard deviation divided by the mean for the respective periods 2000-2004 and 2005-2009. One of the major advantages of the $\mathrm{CV}$ is that it is scale invariant, providing a comparable measure of variation for households that may have very different income levels.

We argue that climate variability, proxied by the $\mathrm{CV}$, is a major determinant of welfare in rural areas as a result of the dependence on agriculture for subsistence consumption and livelihoods. This consideration is distinct from the literature, which examines the effects of weather shocks on welfare using 
the level of rainfall or deviation from its mean. Weather shocks are clearly important for welfare, as a broad literature has already shown; however, the focus of this paper is on climate variability as a proxy for future income uncertainty. While the level of rainfall or rainfall shocks tend to be used as instrumental variables or proxy variables for income or covariate income shocks, there are limitations to this (Rosenzweig and Wolpin, 2000), including identification issues. For example, more rainfall is usually defined as good, i.e., the coefficient is positive; however, even controlling for a quadratic rainfall term - expected to have a negative coefficient, indicating diminishing returns to rainfall - may not be sufficient identification. If farmers form expectations about the climatic conditions of their area, we might expect that they plant crops that are suited to that area. Any deviation from the conditions on which this optimal cropping decision is based, such as more or less rainfall, may not be welfare-improving. The formation of these expectations is key for production. For this reason, we focus on climate variability, which, we argue, generates uncertainty about the likelihood of future weather shocks. It is important to control for recent rainfall shocks as this is likely to be correlated with the CV. We include a dummy variable equal to one if the village has experienced a negative rainfall shock one standard deviation below the long-run mean in the previous 5 years. While this measure allows us to observe the realisation of rainfall shocks over the 5-year period, it is likely that a shock in the previous year would have the greatest impact on SWB. Our results are also robust to contemporaneous rainfall shocks in the most recent agricultural year. ${ }^{11}$

Questions relating to the respondents' personal characteristics have been selected based on earlier studies on happiness, comprising the respondent's age, gender, unemployment status, marital status, education, religion and health status.

The household-level variables we control for include the relative position of the household within the community - an indicator variable to a perceived change in living standard over the past three years -, social capital proxied

\footnotetext{
${ }^{11}$ The results controlling for the impact of contemporaneous rainfall shocks are reported in table 5 of appendix $\mathrm{C}$. The results remain robust to this specification.
} 
by an increase or decrease in the number of persons available to help the household in a time of need, household size, and measures of economic status captured by the stock of livestock and real consumption expenditure per capita. The relative position variable has been constructed from the responses given to the question "Compared to other households in the village, would you describe your household as: the richest in the village; richer than most households; about average; a little poorer than most households; the poorest in the village?".

The stock of livestock the household owns is measured in livestock-equivalent units, and real consumption per capita is adjusted for adult-equivalent units. The consumption measure was calculated using the approach used by Dercon \& Krishnan (1996), which aggregates consumption on both food and non-food expenditures. Nominal consumption expenditures reported by households have been converted into real consumption expenditures using carefully constructed price indices from the survey. The consumption variable has been adjusted for both spatial and temporal price differences.

Table 2 presents the key descriptive statistics of variables for the period analysed (the full table is available in Appendix A) and table 3 below presents the distribution of annual rainfall by village.

Rainfall in Ethiopia is low and erratic. From table 3, we observe that there is considerable inter-annual variability, as well as variability across the villages of study. The average rainfall across all the villages for the period 1995-2008 is just under $1000 \mathrm{~mm}$ per annum, though there is considerable heterogeneity. For example, Haresaw and Geblen, villages from the Tigray region in Northern Ethiopia, experienced an average of around $400 \mathrm{~mm}$ per annum between 1979 and 2009. Some villages also experience significant inter-annual variation. Figure 1 in the appendix provides a visualisation of the inter-annual heterogeneity in rainfall, as well as a demonstration of the degree to which the villages in the sample represent the average climate of Ethiopia. Figure 2 in the appendix shows density plots for the coefficient of variation over the two periods for which we have economic data, demonstrating the temporal variation we observe. Figures 4-6 in the appendix provide a visualisation of 
the spatial heterogeneity.

\subsection{Empirical Strategy}

We examine the effect of climate variability on SWB using the variables defined in the previous section. The model we present is estimated using a differencein-means estimation approach (i.e., fixed-effects or "within" regression) with cluster-robust Huber-White standard errors at the village level to account for serial correlation within villages. This allows us to address the issue of time-invariant unobserved individual heterogeneity, which has been shown to be important in studies examining the determinants of SWB. ${ }^{12}$ In addition to individual fixed effects, we control for year fixed effects to control for aggregate shocks, economic development, and macroeconomic policies. We also include month fixed effects to control for seasonal variation in the timing of the survey.

The model is estimated using the following specification:

$$
\mathrm{W}_{i t}=\alpha_{i}+\beta_{1} \mathrm{CV}_{v t}+\beta_{2} \mathrm{SHOCK}_{v t}+\beta_{3} \mathrm{X}_{i t}+\beta_{4} \mathrm{X}_{h t}+\alpha_{m}+\alpha_{t}+\epsilon_{i t}
$$

where subscripts index individual, $i$, household, $h$, village, $v$, month, $m$ and year, $t . \mathrm{W}_{i t}$ is the level of life satisfaction reported by an individual $i$ at time t. $\mathrm{CV}_{v t}$ corresponds to the coefficient of variation at the village level, which captures anticipatory utility. We also include $\mathrm{SHOCK}_{v t}$, a dummy variable equal to one if the village has experienced a negative rainfall shock in the past 5 years greater than or equal to a one-standard deviation deficiency below the long-run mean, which captures memory utility. In addition to these core variables, we include a set of controls and characteristics, X, measured at the individual and household level, that are determinants of current utility. $\alpha_{i}$ corresponds to the individual fixed effect, $\alpha_{t}$ to the year fixed effect, and $\alpha_{m}$ to the month fixed effect. $\epsilon_{i v t}$ is a time-varying random shock. Given that climate variability is random, and assuming that, in the absence of changes in

\footnotetext{
${ }^{12}$ Table 4 of appendix $\mathrm{C}$ replicates the results from table 4 , using village fixed effects as an alternative to individual fixed effects. The results are robust to this specification.
} 
variability, $\mathrm{W}_{i t}$ would have remained the same, the parameter $\beta_{1}$ will represent the causal effect of climate variability on the life satisfaction of smallholder farmers in rural Ethiopia. More formally, in the absence of any change in climate variability, $\beta_{1}$ would not be statistically different from zero. Given that we control for time-invariant unobserved heterogeneity using individual fixed effects, and attempt to control for other confounding variables that may be correlated with our measure of climate variability (e.g., whether there was a negative rainfall shock in the same measurement period, the rainfall and temperature on the day of the survey to capture potential weather bias, etc.) we believe that the results presented below, along with the additional evidence provided by the robustness checks, support a causal interpretation.

As a robustness check, we can extend this approach by applying an ordered probit with random effects to (1) to account for an ordinal measure of life satisfaction rather than a cardinal measure. The use of linear regression models implies that the spacing between different outcomes, e.g., "Very Satisfied" and "Dissatisfied", or "Satisfied" and "Very Satisfied", are uniform. The use of an ordered probit model assumes that the respondent's well-being $\mathrm{W}$, is an unobserved latent outcome conventionally proxied by a self-reported life satisfaction response, $\mathrm{W}^{*}$, on an ordinal scale. However, since it is not possible to formulate a fixed effects ordered probit model as the fixed effects are not conditioned out of the likelihood, we must use random effects.

However, one issue regarding the random-effects ordered probit model, indeed any random-effects model, is the strong and often unrealistic assumption that the unobserved individual heterogeneity term $\alpha_{i}$ is independent of the observable regressors $\mathrm{X}_{i t}$, i.e., $\mathbb{E}\left(\epsilon_{i t} \mid \alpha_{i}, \mathrm{X}_{i t}\right)=0$. Because of this strong assumption, random-effects models tend to be avoided by economists and other social scientists due to issues of bias and uncertainty (Hausmann \& Taylor, 1981). As unmeasurable individual heterogeneity has been shown to be an important determinant of life satisfaction (Argyle, 1999; Diener \& Lucas, 1999; Ferrer-i-Carbonell \& Frijters, 2004), we report results from both linear and non-linear models with fixed and random effects to test the consistency of our results across models. 


\section{Results}

Table 4 presents results from generalised least squares with random effects $(\mathrm{RE})$, ordinary least squares with fixed effects $(\mathrm{FE})$, and an ordered probit model with RE to account for differences in whether one assumes cardinality or ordinality in life satisfaction data, exploring whether climate variability affects the life satisfaction of farmers surveyed in the ERHS. Table 1 in appendix B presents these results with the full set of variables. Table 2 in appendix A provides the marginal effects for the ordered probit model.

We can see that the coefficient for climate variability is negative and statistically significant at the $5 \%$ level in the most robust specification, controlling for fixed effects, an indication that anticipatory utility does enter into the utility function of farmers, which is in line with the theory of optimal expectations. The signs and qualitative trade-off between the coefficients are relatively similar, suggesting that there is little difference in the interpretation of the results whether one assumes cardinality or ordinality in the life satisfaction data (Ferrer-i-Carbonell \& Frijters, 2004). These results provide point estimates of the effect of climate variability on life satisfaction between -0.047 and -0.077 for a one-unit increase in the coefficient of variation. This corresponds to approximately $2.67-4.37 \%$ of the standard deviation in the life satisfaction responses. Following a one standard deviation increase in climate variability, we would expect a decline in life satisfaction equivalent to 20.5$33.68 \%$ of a one standard deviation in life satisfaction responses. To emphasise the potential welfare impact of climate variability, we note that this is equivalent to around a two standard deviation (1-2\%) decrease in real household consumption per capita. The magnitude of this effect is considerable. Indeed, compared to the other determinants of life satisfaction examined in this paper, climate variability is shown to be one of the largest.

Importantly, our results also reveal that present income (proxied by real consumption expenditure per capita), has a positive impact on life satisfaction. While there are clear endogeneity issues, it is important to control for income to ensure that our measure of climate variability is not capturing any indirect 
impact on well-being through present consumption.

\section{$6 \quad$ Supporting Evidence}

As well as showing the robustness of our results to different linear and nonlinear models, we consider a number of additional extensions and robustness checks to try and disentangle the channel observed in the reduced-form results. This analysis in this section uses the most robust specification from the main analysis (the FE model).

First, we attempt to test our identifying assumption that climate variability impacts well-being through future income uncertainty and not other channels by examining the impact of $\mathrm{CV}$ on real consumption per capita to examine indirect effects through income.

Second, we attempt to close out the channel that increased climate variability reduces social networks through the impact that covariate risk management might have on self-insurance groups. As argued, actions to reduce exposure to covariate risk may have detrimental effects on informal insurance groups. If climate variability impacts life satisfaction only through increased stress about future income uncertainty, then we should find no effect on consumption, social networks or self-insurance.

Third, we test our results through the use of placebo effects by looking at seasonal climate variability. We should observe that only variability during the rainy season matters, particularly the Belg season, as this is when decisionmaking occurs (Bezabih \& Sarr, 2012). Generally, farmers in Ethiopia plant slow-maturing but high-yielding 'long-cycle' crops that grow across both the Belg and Kiremt seasons. We argue that while the Kiremt season rainfall is important for the final yield, the Belg rains are most important as a determinant of crop failure. If there is not sufficient rainfall during the Belg season for seeds to germinate, then Kiremt season rainfall is less important.

Fourth, we investigate whether climate variability affects SWB of urban Ethiopian households, who do not directly depend on the rains for their livelihood. 
Finally, we examine the impact of climate variability on alternative measures of SWB. We compare our results using the standard life satisfaction measure to results using the Cantril ladder measure and a measure of happiness. While these measures should display similar results, we exploit what we argue is an implicit time dimension in the way that these questions are interpreted. When being asked whether you are satisfied in your life or where on the Cantril ladder (an alternative measure of life satisfaction), individuals consider their lives as a whole. By contrast, when asked if an individual is happy, this is more likely to capture contemporaneous "happiness". We argue that if climate variability is capturing the impact of future income uncertainty then we should find no effect on "happiness". By contrast, weather effects such as rainfall and temperature on the day of the survey, if important, should matter for "happiness".

Appendix B also includes a number of additional robustness tests to check the validity of our results to alternative specifications and outliers. These include: changing the period of time over which we define the coefficient of variation; alternative definitions of climate variability; more mechanical robustness tests.

\subsection{The Impact of Climate Variability on Consumption and Social Networks}

Table 5 provides support to our hypothesis that climate variability reduces life satisfaction through future income uncertainty. We observe that there is no effect of climate variability on real consumption per capita and no effect of climate variability on potential risk management channels. As further evidence that we are identifying ex ante components of climate, separate from ex post impacts, we observe that negative rainfall shocks reduce real consumption expenditure per capita. 


\subsection{Seasonal Variability}

Table 6 shows the results from the various seasonal measures of climate variability. We observe that Belg season variability is important while Kiremt season and Bega (dry) season variability is not. This supports our hypothesis that climate variability affects life satisfaction through stress resulting from future income uncertainty, as critical decision-making occurs in the Belg season. As stated above, Belg rainfall is critical for agricultural output in Ethiopia, even more so than the main Kiremt rainy season, as there needs to be sufficient rainfall for seeds to germinate. A lack of rainfall in the Belg season may result in complete crop failure, whereas reductions in rainfall in the Kiremt season is likely to only reduce yields. Bezabih \& Marr (2012) provide supporting evidence for this hypothesis by demonstrating that increased Belg season climate variability has a positive effect on the extensive margin of crop diversification - a risk management strategy.

\subsection{Rural vs. Urban Differences in the Impact of Cli- mate Variability on SWB}

Table 7 examines the impact of climate variability on SWB in urban Ethiopia. If we expect that climate variability affects SWB through future income uncertainty, then we should expect to see no effect of climate variability on SWB in urban areas, where livelihood does not directly depend on rain. ${ }^{13}$

We use three rounds of panel data from the Ethiopian Urban Socio-economic Survey (EUSS) in 2000, 2004, and 2009. This data consists of four cities selected to represent the major urban areas of Ethiopia: Addis Ababa, Awassa, Dessie, and Mekelle. ${ }^{14}$

Unlike our rural data, we are only able to control for household fixed effects, not individual fixed effects; however, we try to match the specification

\footnotetext{
${ }^{13}$ We acknowledge the caveat that climate variability could be argued to impact urban areas through general equilibrium effects on food prices; however, this is more likely to result from the realisation of shocks than climatic variability.

${ }^{14}$ See Alem \& Söderbom (2012) for more detail on this data set.
} 
as closely as possible to the model used in the main results to increase the credibility of our findings.

The results from table 7 demonstrate that SWB in urban areas is unaffected by climate variability or climate shocks in the previous 5 years. While there are limitations to this data in terms of the amount of spatial variation we can capture, we argue that the magnitude of the coefficients is small enough to support our claim, even in the event of type I error.

\subsection{Alternative Measures of SWB}

In addition to alternative definitions of the explanatory variable, we also consider alternative dependent variables. Within the SWB literature, it is generally considered that questions based on the life satisfaction scale and the Cantril ladder scale are more evaluative measures, whereas questions related to happiness are a better measure of present affect (Benjamin et al., 2013; Levinson, 2013). ${ }^{15}$ Given the proposed channel through which we would expect climate variability to effect SWB, we should find similar results using the Cantril ladder scale. We do not expect that climate variability is likely to have an effect on present happiness, however, since we expect that the impact on well-being is based on uncertainty about future income.

Consistent with this hypothesis, we observe in table 7 that climate variability measured annually and for the Belg season, has a negative and statistically significant effect on both life satisfaction and responses to the Cantril ladder scale; however, we observe no effect on happiness, even though all the measures are positively correlated. This indicates that the happiness responses may provide a measure of subjective well-being based on present mood, while life satisfaction and the Cantril ladder scale provide more evaluative measures of subjective well-being. This conjecture is further supported by the evidence

\footnotetext{
${ }^{15}$ The Cantril ladder scale is measured based on the following question: "Suppose we say that the top of a ladder represents the best possible life for you and the bottom represents the worst possible life for you, where on the ladder do you feel you personally stand at the present time?". The Happiness question, "Taken all together, how would you say things are for you these days? Would you say you are:" is measured on a 3-step likert scale with the responses: Not too happy; Pretty happy; Very happy.
} 
in table 7 that average temperature on the day of the survey has a positive impact on happiness, while having no impact on the more evaluative measures. This demonstrates the importance of considering the time dimension implicit within questions on SWB when drawing policy implications from results.

Given the robustness of our results to the various extensions and tests shown here and in appendix $\mathrm{C}$, we argue that the impact that climate variability has on farmers' SWB in rural Ethiopia is plausibly explained by the experienced utility effect of future income uncertainty. Given the lack of access to well-functioning, formal insurance markets to deal with rainfall variability and the associated risk, it is not surprising that increased climate variability, capturing future income uncertainty, has a significant impact on reported subjective well-being.

\section{Conclusion}

In this paper we investigated the impact of future income uncertainty, proxied by climate variability, on the subjective well-being of rain-dependent farmers in Ethiopia by matching two rounds of household-level panel-data with a long series of atmospheric data supplied by the European Centre for MediumTerm Weather Forecasting (ECMWF). We implemented a series of linear and non-linear panel data models that control for time-invariant unobserved heterogeneity and performed a number of robustness tests, which help to support the main identification assumption of this research question - that climate variability has no impact on experienced utility other than through uncertainty about future states of the world. Of particular importance is our ability to control for the level of rainfall and temperature on the day that each respondent was surveyed and disentangle the effects of climate variability from that of weather. Based on our parameter estimates, we computed the welfare cost of climate variability in terms of equivalent economic loss.

Fixed-effects regression results suggest that climate variability has a significant adverse impact on the SWB of farm households in rural Ethiopia. A one standard deviation increase in climate variability is associated with a decrease 
in life satisfaction equivalent to a $2 \%$ decrease in real consumption per capita. We show this to be one of the largest determinants of life satisfaction in rural Ethiopia. This result indicates that anticipatory utility is an important determinant of well-being in rural Ethiopia, in line with the theory of optimal expectations (Brunnermeier \& Parker, 2005). We rule out indirect channels related to effects on consumption and social network changes and demonstrate that climate variability outside the Belg season is not important for life satisfaction. Removing these channels is important as they emphasise the channel which, we argue, underpins our results: that stress resulting from future income uncertainty has a negative impact on well-being. Belg season variability is arguably the most important determinant for future income uncertainty as this is the period in which production decisions occur. Furthermore, there needs to be sufficient rainfall for seeds to germinate. A lack of rainfall in the Belg season may result in complete crop failure, whereas reductions in rainfall in the Kiremt season are likely only to reduce yields. Interestingly, we show that climate variability does not have any statistically significant impact on SWB of respondents in urban Ethiopia, whose livelihoods do not directly depend on rain.

Results also confirm the importance of other conventional correlates of SWB that were found to be important in studies in other developed and developing countries, indicating the consistency of these relationships.

We argue that investigating the impact of climate variability on SWB in rural Ethiopia offers useful insights into the welfare costs of climatic influence. Our observation that climate variability affects the welfare of farmers increase the potential welfare cost of climate change, reinforcing the findings of earlier studies that explore the adverse impact of a changing climate on objective indicators such as agricultural yield and income. Furthermore, we observe that the main impact of climate variability on well-being arises because of uncertainty about future income in concordance with the theory of optimal expectations. As a result, increased access to ex post coping mechanisms such as insurance, and ex ante risk management strategies, as well as increased information to help farmers to form better subjective probabilities about the likelihood of 
future shocks, are likely to reduce the importance of anticipatory utility, increasing welfare. Future research questions relate to how optimal expectations affect decision-making under uncertainty. However, if we expect that individuals living in areas with lower climate variability are more optimistic about future states of the world, they may invest less in risk-management and consequently may experience greater welfare losses than areas with high climate variability in the event that bad states are realised. If true, we may expect under-investment adaptation strategies, reducing the difference between the short-run (weather) and long-run (climate) elasticity of climatic influence on economic outcomes and welfare. 


\section{References}

Alem, Y. and G. Köhlin (2012). Life satisfaction and household factors: Panel data evidence from urban ethiopia. Department of Economics, University of Gothenburg.

Alem, Y. and P. Martinsson (2011). What do policymakers know about the factors influencing citizens' subjective well-being? Department of Economics, University of Gothenburg.

Alem, Y. and M. Söderbom (2012). Household-level consumption in urban ethiopia: The effects of a large food price shock. World Development 40 , 146-62.

Alesina, A., R. Di Tella, and R. MacCulloch (2004). Inequality and happiness: are europeans and americans different? Journal of Public Economics 88, 2009-2042.

Alpert, M. and H. Raiffa (1982). A progress report on the training of probability assessors. In D. Kahneman, P. Slovic, and A. Tversky (Eds.), Judgment under uncertainty: Heuristics and biases., pp. 293-305. Cambridge University Press.

Appleton, S. and L. Song (2008). Life satisfaction in urban china: Components and determinants. World Development 36(11), 2325-2340.

Argyle, M. (1999). Well-Being: The Foundations of Hedonic Psychology: Scientific Perspectives on Employment and Suffering., Chapter Causes and Correlates of Happiness., pp. 353-373. New York: Russel Sage Foundation.

Auffhammer, M., S. Hsiang, W. Schlenker, and A. Sobel (2013). Using weather data and climate model output in economic analyses of climate change. Review of Environmental Economics nad Policy.

Barreca, A., K. Clay, O. Deschênes, M. Greenstone, and J. Shapiro (2013). Adapting to climate change: The remarkable decline in the u.s. temperaturemortality relationship over the 20th century. NBER Working Paper 18692. 
Benjamin, D., M. Ori Heffetz, M. Kimball, and N. Szembrot ((forthcoming)). Aggregating local preferences to guide marginal policy adjustments. American Economic Review: Paper and Proceedings.

Bezabih, M. and M. Sarr (2012). Risk preferences and environmental uncertainty: Implications for crop diversification decisions in ethiopia. Environmental and Resource Economics 53(4), 483-505.

Blanchflower, D. and A. Oswald (2004). Money, sex, and happiness: An empirical study. Scandinavian Journal of Economics 106(3), 333-353.

Boarini, R., M. Comola, C. Smith, R. Manchin, and F. De Keulenaer (2012). What makes for a better life? the determinants of subjective well-being in oecd countries: Evidence from the gallup world poll. Technical report, OECD WP47.

Bookwalter, J. and D. Dalenberg (2004). Subjective well-being and household factors in south africa. Social Indicators Research 65(3), 333-353.

Bookwalter, J. and D. Dalenberg (2010). Relative to what or whom? the importance of norms and relative standings to well-being in south africa. World Development 38(3), 345-355.

Brunnermeier, M. and J. Parker (2002). Optimal expectations. Princeton University, Woodrow Wilson School Discussion Paper in Economics No. 221.

Brunnermeier, M. and J. Parker (2005). Optimal expectations. American Economic Review 95(4), 1092-1118.

Buehler, R., D. Griffin, and M. Ross (1994). Exploring the "planning fallacy": Why people underestimate their task completion times. Journal of Personality and Social Psychology 67(3), 366-81.

Burgess, R., O. Deschenes, D. Donaldson, and M. Greenstone (2011). Weather and death in india. Mimeo. 
Caplin, A. and J. Leahy (2004). The supply of information by a concerned expert. The Economic Journal 114(497), 487-505.

Caplin, A. and J. Leahy (2005). Psychological expected utility theory and anticipatory feelings. Quarterly Journal of Economics 116(1), 55-79.

Carroll, N., P. Frijters, and M. Shields (2009). Quantifying the costs of drought: New evidence from life satisfaction data. Journal of Population Economics 22(2), 445-461.

Clark, A., P. Frijters, and M. Shields (2007). Relative income, happiness and utility: an explanation for the easterlin paradox and other puzzles. Journal of Economic Literature 46(1), 95-144.

Colmer, J. (2013). Climate variability, child labour, and schooling: Evidence on the intensive and extensive margin. Centre for Climate Change Economics and Policy Working Paper No. 148.

Davies, S. and T. Hinks (2008). Life satisfaction in malawi and the importance of relative consumption, polygamy and religion. Journal of International Development 20(7), 888-904.

Davies, S. and T. Hinks (2010). Crime and happiness amongst heads of households in malawi. Journal of Happiness Studies 11(4), 457-476.

Dee, D. P., S. M. Uppala, A. J. Simmons, P. Berrisford, P. Poli, S. Kobayashi, U. Andrae, M. A. Balmaseda, G. Balsamo, P. Bauer, P. Bechtold, A. C. Beljaars, L. M., van de Berg, J. Bidlot, N. Bormann, C. Delsol, R. Dragani, M. Fuentes, A. J. Geer, L. Haimberger, S. B. Healy, H. Hersbach, E. V. Hólm, L. Isaksen, P. Kållberg, M. Köhler, M. Matricardi, A. P. McNally, B. Monge-Sanz, J. Morcrette, B. Park, C. Peubey, P. de Rosnay, C. Tavolato, J. Thépaut, and F. Vitart (2011). The era-interim reanalysis: configuration and performance of the data assimilation system. Quarterly Journal of the Royal Meteorological Society 137, 553-597. 
Delgado, M. and A. Porcellie (2009). Acute stress modulates risk taking in financial decision making. Psychological Science 20(3), 278-283.

Dell, M., B. Jones, and B. Olken (2012). Temperature shocks and economic growth: Evidence from the last half century. American Economic Journal: Macroeconomics 4(3), 66-95.

Dercon, S. and J. Hoddinott (2009). The ethiopian rural household surveys 1989 - 2004: Introduction. IFPRI.

Dercon, S. and P. Krishnan (1996). Income portfolios in rural ethiopia and tanzania: Choices and constraints. Journal of Development Studies 32(6).

Deschênes, O. and M. Greenstone (2007). The economic impacts of climate change: Evidence from agricultural output and random fluctuations in weather. American Economic Review 97(1), 354-385.

Deschênes, O. and M. Greenstone (2012). The economic impacts of climate change: Evidence from agricultural output and random fluctuations in weather: Reply. American Economic Review 102(7), 3761-3773.

Devoto, F., E. Duflo, P. Dupas, W. Pariente, and V. Pons (2012). Happiness on tap: Piped water adoption in urban morocco. American Economic Journal: Economic Policy 4(4), 68-99.

Diener, E. and M. Chan (2011). Happy people live longer: Subjective wellbeing contributes to health and longevity. Applied Psychology: Health and Well-Being 3(1), 1-43.

Diener, E. and R. Lucas (1999). Well-Being: The Foundations of Hedonic Psychology: Scientific Perspectives on Employment and Suffering., pp. 213229. New York: Russel Sage Foundation.

Diener, E., R. Lucas, U. Schimmack, and J. Helliwell (2009). Well-Being for Public Policy. New York: Oxford University Press. 
Doherty, T. and S. Clayton (2011). The psychological impacts of global climate change. American Psychologist 66(4), 265-276.

Dolan, P. and D. Kahneman (2008). Interpretations of utility and their implications for the valuation of health. The Economic Journal 118(525), 215-234.

Dolan, P., R. Layard, and R. Metcalfe (2011). Measuring subjective well-being for public policy. Technical report, Office for National Statistics, UK.

Feddersen, J., R. Metcalfe, and M. Wooden (2012). Subjective well-being: Weather matters; climate doesn't. Technical report, Melbourne Institute Working Paper Series WP25/12.

Ferreira, S., A. Akay, F. Brereton, J. Cunado, P. Martinsson, and M. Moro (2012). Life satisfaction and air quality in europe. IZA Discussion Paper No.6732 July.

Ferreira, S. and M. Moro (2010). On the use of subjective well-being data for environmental valuation. Environmental and Resource Economics 46(3), 249-273.

Ferrer-i-Carbonell, A. and P. Frijters (2004). How important is methodology for the estimates of the determinants of happiness? Economic Journal 114(497), 641-659.

Ferrer-i-Carbonell, A. and J. Gowdy (2007). Environmental degradation and happiness. Ecological Economics 60(3), 509-516.

Fisher, A., M. Hanemann, W. Schlenker, and M. Robers (2012). The economic impacts of climate change: Evidence from agricultural output and random fluctuations in weather: Comment. American Economic Review 102(7), 3749-3760.

Frey, B. and A. Stutzer (2002). Happiness and Economics. Princeton University Press, Princeton, N.J., USA. 
Frey, B. Luechinger, S. and A. Stutzer (2007). Calculating tragedy: assessing the costs of terrorism. Journal of Economic Surveys 21, 1-24.

Gollier, C. (2005). Optimal illusions and decision under risk. CESIFO Working Paper No.1382.

Graham, C. and S. Pettinato (2001). Frustrated achievers: Winners, losers, and subjective well being in new market economies. Brookings Institute, Center on Social and Economic Dynamics, Working Paper no.21.

Graham, C. and S. Pettinato (2002). Happiness and Hardship: Opportunity and Insecurity in New Market Economies. Washington D.C: The Brookings Institution Press.

Gruber, J. and S. Mullainathan (2005). Do cigarette taxes make smokers happier? The B.E. Journal of Economic Analysis $\mathcal{E}$ Policy 5(1).

Guiteras, R. (2009). The impact of climate change on indian agriculture. Mimeo.

Hare, T., C. Camerer, and A. Rangel (2009). Self-control in decision-making involves modulation of the vmpfc valuation system. Science 324, 646-648.

Hausman, J. and W. Taylor (1981). Panel data and unobservable individual effects. Econometrica 49(6), 1377-1398.

Hsiang, S., K. Meng, and M. Cane (2011). Civil conflicts are associated with the global climate. Nature 476, 438-441.

IPCC (2007). Climate change 2007: Synthesis report. contribution of working groups i, ii and iii to the fourth assessment report of the intergovernmental panel on climate change. Technical report.

IPCC (2012). Managing the risks of extreme events and disasters to advance climate change adaptation. a special report of working groups $i$ and ii of the ipcc. Technical report. 
Kahneman, D. and A. Krueger (2006). Developments in the measurement of subjective well-being. The Journal of Economic Perspectives 20(1), 3-24.

Kahneman, D., W. P. and R. Sarin (1997). Back to bentham? explorations of experienced utility. Quarterly Journal of Economics 112, 375-405.

Kingdon, G. and J. Knight (2006). Subjective well-being poverty vs. income poverty and capabilities poverty? Journal of Development Studies 42(7), $1199-1224$.

Knight, J. and R. Gunatilaka (2010). Great expectations? the subjective wellbeing of rural-urban migrants in china. World Development 38(1), 113-124.

Knight, J., L. Song, and R. Gunatilaka (2009). The determinants of subjective well-being in rural china. China Economic Review 20(2), 635-649.

Kozegi, B. (2003). Health anxiety and patient behavior. Journal of Health Economics 22(6), 1073-1084.

Kozegi, B. (2006). Emotional agency. Quarterly Journal of Economics 121(1), $121-155$.

Kudamatsu, M., T. Persson, and D. Stromberg (2012). Weather and infant mortality in africa. CEPR Discussion Paper No. 9222.

Levinson, A. (2012). Valuing public goods using happiness data: The case of air quality. Journal of Public Economics 96(10), 869-880.

Levinson, A. (2013). Happiness, behavioural economics, and public policy. NBER Working Paper 19329.

Lorenz, C. and H. Kuntsmann (2012). The hydrological cycle in three stateof-the-art reanalyses: intercomparison and performance analysis. Journal of Hyrdrometeorology 13(5), 1397-1420.

Luechinger, S. (2009). Valuing air quality using the life satisfaction approach. The Economic Journal 119, 482-515. 
McKerron, G. (2011). Happiness economics from 35,00 feet. Journal of Economic Surveys.

Metcalfe, R., N. Powdthavee, and P. Dolan (2011). Destruction and distress: Using a quasi-experiment to show the effects of the september 11 attacks on mental well-being in the united kingdom. The Economic Journal 121(550), 81-103.

Oster, E., I. Shoulson, and R. Dorsey (forthcoming). Optimal expectations and limited medical testing: Evidence from huntington disease. American Economic Review.

Qian, X. and R. Smyth (2008). Inequality and happiness in urban china. Economics Bulletin 4 (24), 1-10.

Rabin, M. and J. Schrag (1999). First impressions matter: A model of confirmatory bias. The Quarterly Journal of Economics 114(1), 37-82.

Ravallion, M. and M. Lokshin (2005). Rich and powerful? subjective power and welfare in russia. Journal of Economic Behaviour and Organization 56(2), 141-172.

Rehdanz, K. and D. Maddison (2005). Climate and happiness. Ecological Economics 52(1), 111-125.

Rehdanz, K. and D. Maddison (2008). Local environmental quality and life satisfaction in germany. Ecological Economics 64(4), 787-797.

Rosenzweig, M. and K. Wolpin (2000). Natural "natural experiments" in economics. Journal of Economic Literature 38(4), 827-874.

Schlenker, W. and D. Lobell (2010). Robust negative impacts of climate change on african agriculture. Environmental Research Letters 5, 1-8.

Schlenker, W. and M. Roberts (2009). Nonlinear temperature effects indicate severe damages to us crop yields under climate change. Proceedings of the National Academy of Sciences 106 (37), 15594-98. 
van den Bos, R., M. Harteveld, and H. Stoop (2009). Stress and decisionmaking in humans: Performance is related to cortisol reactivity, albeit differently in men and women. Psychoneuroendocrinology 34 (10), 1449-1458.

Weinstein, N. (1980). Unrealistic optimism about future life events. Journal of Personality and Social Psychology 39(5), 806-20.

Welsch, H. (2002). Preferences over prosperity and pollution: Environmental valuation based on happiness surveys. Kyklos 55, 473-494.

Welsch, H. (2006). Environment and happiness: evaluation of air pollution using life satisfaction data. Ecological Economics 58, 801-813.

Welsch, H. and J. Kuehling (2009). Using happiness data for environmental valuation: issues and applications. Journal of Economic Surveys 23, 385406. 
Table 1: Life Satisfaction Responses from Full Sample

\begin{tabular}{lccc}
\hline & 2004 & 2009 & $(2004-2009)$ \\
\hline Mean Satisfaction & 3.82 & $4.09 \%$ & 3.97 \\
\hline Very Dissatisfied & $6.81 \%$ & $7.32 \%$ & $7.08 \%$ \\
Dissatisfied & $24.37 \%$ & $20.79 \%$ & $22.47 \%$ \\
Slightly Dissatisfied & $16.25 \%$ & $13.14 \%$ & $14.59 \%$ \\
Neither & $7.08 \%$ & $7.32 \%$ & $7.21 \%$ \\
Slightly Satisfied & $24.92 \%$ & $22.54 \%$ & $23.66 \%$ \\
Satisfied & $18.33 \%$ & $22.69 \%$ & $20.64 \%$ \\
Very Satisfied & $2.25 \%$ & $6.20 \%$ & 4.35 \\
\hline Total & $100 \%$ & $100 \%$ & $100 \%$ \\
Observations & 1815 & 2062 & 3877 \\
\hline
\end{tabular}

Table 2: Summary statistics

\begin{tabular}{lccc}
\hline \multicolumn{1}{c}{ Variable } & Mean & Std. Dev. & $\mathrm{N}$ \\
\hline Climate Variables & & & \\
Climate Variability & 22.98 & 7.71 & 3877 \\
Rainfall Shock (Past 5 years) & 0.712 & 0.45245 & 3877 \\
Rainfall (mm) (Day of Survey) & 3.42 & 4.65 & 3877 \\
Temperature (Day of Survey) & 26.65 & 0.829 & 3877 \\
Respondent variables & & & \\
Age & 46.612 & 15.203 & 3774 \\
Female & 0.41 & 0.49 & 3877 \\
Unemployed & 0.016 & 0.126 & 3877 \\
Married* & 0.764 & 0.425 & 3773 \\
Single & 0.045 & 0.208 & 3773 \\
Divorced & 0.045 & 0.207 & 3773 \\
Widowed & 0.146 & 0.353 & 3773 \\
No Schooling & 0.563 & 0.496 & 3877 \\
Grades 1-7 & 0.207 & 0.405 & 3877 \\
Grades 8 plus & 0.049 & 0.216 & 3877 \\
Household variables & & & \\
Log Real Consumption per capita & 3.973 & 0.776 & 3873 \\
Log Household Size & 1.676 & 0.507 & 3873 \\
Richest & 0.011 & 0.104 & 3869 \\
Richer than Most & 0.123 & 0.3288 & 3869 \\
Average* & 0.516 & 0.49 & 3869 \\
Poorer than Most & 0.456 & 0.384 & 3869 \\
Poorest & 0.053 & 0.225 & 3869 \\
\hline * denotes reference group & & &
\end{tabular}

$*$ denotes reference group. 
Table 3: Annual Rainfall (mm) by Peasant Authority and Year

\begin{tabular}{lccccc}
\hline Peasant Association & 2004 & 2009 & mean & std. dev. & CV \\
\hline Haresaw & 395 & 470 & 476 & 155 & 33.12 \\
Geblen & 226 & 261 & 278 & 95 & 34.24 \\
Dinki & 810 & 865 & 853 & 162 & 18.61 \\
Yetmen & 667 & 713 & 740 & 149 & 20.00 \\
Shumsheha & 535 & 627 & 645 & 150 & 23.34 \\
Sirbana Godeti & 1150 & 1218 & 1086 & 172 & 15.61 \\
Adele Keke & 1175 & 1169 & 1008 & 177 & 17.19 \\
Korodegaga & 1478 & 1589 & 1364 & 218 & 15.60 \\
Turfe Kechemane & 1170 & 1177 & 1024 & 197 & 18.86 \\
Imbidir & 1051 & 1062 & 936 & 158 & 16.68 \\
Aze Deboa & 1232 & 1253 & 1073 & 210 & 19.08 \\
Addado & 1258 & 1399 & 1188 & 305 & 25.29 \\
Gara Godo & 1546 & 1520 & 1318 & 271 & 20.16 \\
Doma & 1134 & 1270 & 1070 & 257 & 23.71 \\
Debre Berhan Villages & 838 & 893 & 855 & 154 & 17.53 \\
\hline The mean std dev. and CV are calculated for the period $1980-2009$.
\end{tabular}


Table 4: Climate Variability and SWB: Results from Alternative Models.

\begin{tabular}{lccc}
\hline Dependent Variable: Life Satisfaction & OPROBIT- RE & RE & FE \\
\hline Climate Variability & $-0.047^{* * *}$ & $-0.077^{* *}$ & $-0.070^{* *}$ \\
& $(0.013)$ & $(0.031)$ & $(0.030)$ \\
Negative Rainfall Shock (past 5 years) & -0.115 & -0.140 & -0.272 \\
& $(0.081)$ & $(0.295)$ & $(0.307)$ \\
Average Temperature (Day of Survey) & 0.030 & 0.091 & 0.313 \\
& $(0.070)$ & $(0.165)$ & $(0.208)$ \\
Rainfall (mm) (Day of Survey) & -0.001 & -0.003 & -0.014 \\
& $(0.002)$ & $(0.006)$ & $(0.009)$ \\
Log Real Consumption per capita & $0.220^{* * *}$ & $0.300^{* * *}$ & $0.373^{* * *}$ \\
& $(0.031)$ & $(0.059)$ & $(0.109)$ \\
\hline Month dummies & $\mathrm{Y}$ & $\mathrm{Y}$ & $\mathrm{Y}$ \\
Year dummies & $\mathrm{Y}$ & $\mathrm{Y}$ & $\mathrm{Y}$ \\
Village dummies & $\mathrm{Y}$ & $\mathrm{Y}$ & - \\
Individual fixed effects & $\mathrm{N}$ & $\mathrm{N}$ & $\mathrm{Y}$ \\
\hline $\mathrm{N}$ & 3517 & 3517 & 3517 \\
Log-likelihood & -5710.6275 & - & - \\
Adjusted $\mathrm{R}^{2}$ & - & 0.155 & 0.169 \\
\hline
\end{tabular}

OPROBIT-RE, ordered probit with random effects; RE, generalised least squares with random effects; FE, ordinary least squares with fixed effects. Life Satisfaction takes a value of $1=$ Very Dissatisfied, $7=$ Very Satisfied. Control variables include gender, age, age-squared, log of real household consumption per capita, log of livestock owned (tropical livestock units), number of household members, dummies for marital status, unemployment, education, illness experienced in the previous 4 weeks, social network changes, relative income, household standing relative to 3 years ago. Estimates of the control variables are reported in the Appendix. Cluster-robust standard errors at the village level are in parentheses. ${ }^{*} p<0.1,{ }^{* *} p<0.05,{ }^{* * *} p<0.01$ 
Table 5: Climate Variability - Shutting Out Potentially Confounding Channels.

\begin{tabular}{lccc}
\hline Dependent Variable: & Consumption & $\begin{array}{c}\text { Decrease in } \\
\text { Networks } \\
\text { FE }\end{array}$ & $\begin{array}{c}\text { Able to } \\
\text { Borrow Money } \\
\text { FE }\end{array}$ \\
\hline Climate Variability & -0.008 & -0.003 & 0.006 \\
& $(0.019)$ & $(0.004)$ & $(0.009)$ \\
Shock Negative Rainfall & $-0.426^{* *}$ & $-0.125^{* *}$ & -0.045 \\
(past 5 years) & $(0.172)$ & $(0.054)$ & $(0.070)$ \\
\hline Fixed Effects & $\mathrm{Y}$ & $\mathrm{Y}$ & $\mathrm{Y}$ \\
\hline $\mathrm{N}$ & 3,872 & 3,795 & 3,866 \\
Adjusted $\mathrm{R}^{2}$ & 0.2076 & 0.045 & 0.058 \\
\hline
\end{tabular}

Consumption $=\log$ real consumption per capita; Decrease in Networks $=$ There are less people to rely on than 5 years ago, $\mathrm{No}=0$, Yes=1; Able to Borrow Money $=$ If the household needed 100 Birr for an emergency could the household obtain it within a week? Yes $=1, \mathrm{No}=2$. Cluster-robust standard errors at the village level are in parentheses. ${ }^{*} p<0.1,{ }^{* *} p<0.05$, $* * * p<0.01$

Table 6: Seasonal Climate Variability and Life Satisfaction

\begin{tabular}{|c|c|c|c|c|}
\hline & $\begin{array}{l}(1) \\
\mathrm{FE}\end{array}$ & $\begin{array}{l}(2) \\
\mathrm{FE}\end{array}$ & $\begin{array}{l}(3) \\
\mathrm{FE}\end{array}$ & $\begin{array}{l}(4) \\
\mathrm{FE}\end{array}$ \\
\hline Climate Variability $_{B e l g}$ & $\begin{array}{c}-0.0234^{* * *} \\
(0.00628)\end{array}$ & & & $\begin{array}{c}-0.0461^{* *} \\
(0.0175)\end{array}$ \\
\hline Climate Variability Kiremt & & $\begin{array}{c}-0.0171 \\
(0.00981)\end{array}$ & & $\begin{array}{c}0.0217 \\
(0.0218)\end{array}$ \\
\hline Climate Variability $_{B e g a}$ & & & $\begin{array}{l}-0.0186 \\
(0.0268)\end{array}$ & $\begin{array}{l}-0.0322 \\
(0.0253)\end{array}$ \\
\hline Fixed Effects & $\mathrm{Y}$ & $\mathrm{Y}$ & $\mathrm{Y}$ & $\mathrm{Y}$ \\
\hline Observations & 3,610 & 3,610 & 3,610 & 3,610 \\
\hline Adjusted $\mathrm{R}^{2}$ & 0.169 & 0.163 & 0.159 & 0.174 \\
\hline
\end{tabular}

FE, ordinary least squares with fixed effects. Life Satisfaction takes a value of 1 $=$ Very Dissatisfied, $7=$ Very Satisfied. Control variables included as in table 4. Cluster-robust standard errors at the village level are in parentheses. ${ }^{*} p<0.1$, ** $p<0.05, * * * p<0.01$ 
Table 7: Impact of Climate Variability on Life Satisfaction in Urban Ethiopia

\begin{tabular}{lccc}
\hline & $(1)$ & $(2)$ & $(3)$ \\
Dependent Variable: Life Satisfaction & OPROBIT RE & RE & FE \\
\hline Climate Variability & -0.00289 & -0.00128 & 0.00233 \\
& $(0.00577)$ & $(0.0103)$ & $(0.00968)$ \\
Negative Rainfall Shock (past 5 years) & 0.0423 & 0.0392 & 0.192 \\
& $(0.124)$ & $(0.242)$ & $(0.265)$ \\
\hline Year Dummies & Y & Y & Y \\
City Dummies & Y & Y & - \\
Household Fixed Effects & N & N & Y \\
\hline Observations & 2931 & 2931 & 2931 \\
Adjusted $R^{2}$ & & 0.241 & 0.248 \\
\hline
\end{tabular}

FE, ordinary least squares with fixed effects. Life Satisfaction takes a value of 1 = Very Dissatisfied, $4=$ Very Satisfied. Control variables included as in table 4. Cluster-robust standard errors at the city level are in parentheses. ${ }^{*} p<0.1$, ** $p<0.05,{ }^{* * *} p<0.01$

Table 8: Alternative measures of subjective well-being.

\begin{tabular}{|c|c|c|c|c|c|c|}
\hline & $\begin{array}{c}\text { Life } \\
\text { Satisfaction } \\
\text { FE }\end{array}$ & $\begin{array}{c}\text { Life } \\
\text { Satisfaction } \\
\text { FE }\end{array}$ & $\begin{array}{l}\text { Ladder } \\
\text { FE }\end{array}$ & $\begin{array}{l}\text { Ladder } \\
\qquad \text { FE }\end{array}$ & $\begin{array}{l}\text { Happiness } \\
\text { FE }\end{array}$ & $\begin{array}{c}\text { Happiness } \\
\text { FE }\end{array}$ \\
\hline Annual CV & $\begin{array}{c}-0.070^{* *} \\
(0.029)\end{array}$ & & $\begin{array}{c}-0.163^{* * *} \\
(0.024)\end{array}$ & & $\begin{array}{l}-0.016 \\
(0.010)\end{array}$ & \\
\hline Belg CV & & $\begin{array}{c}-0.023^{* * *} \\
(0.020)\end{array}$ & & $\begin{array}{c}-0.039^{* * *} \\
(0.007)\end{array}$ & & $\begin{array}{l}-0.003 \\
(0.001)\end{array}$ \\
\hline Negative Rainfall & $\begin{array}{l}-0.282 \\
(0.304)\end{array}$ & $\begin{array}{c}0.069 \\
(0.320)\end{array}$ & $\begin{array}{l}0.067 \\
(0.053)\end{array}$ & $\begin{array}{l}0.547 \\
(0.310)\end{array}$ & $\begin{array}{l}0.005 \\
(0.096)\end{array}$ & $\begin{array}{l}0.036 \\
(0.102)\end{array}$ \\
\hline $\begin{array}{l}\text { Shock (past } 5 \text { years) } \\
\text { Average Temperature }\end{array}$ & $\begin{array}{c}(0.304) \\
0.321\end{array}$ & $\begin{array}{c}(0.320) \\
0.289\end{array}$ & 0.313 & 0.158 & $0.128^{* *}$ & $0.119^{*}$ \\
\hline (Day of Survey) & $(0.205)$ & $(0.201)$ & $(0.208)$ & $(0.231)$ & $(0.058)$ & $(0.063)$ \\
\hline Rainfall (mm) & -0.014 & -0.014 & $-0.019^{*}$ & $-0.021^{* *}$ & -0.001 & -0.001 \\
\hline (Day of Survey) & $(0.009)$ & $(0.009)$ & $(0.009)$ & $(0.008)$ & $(0.000)$ & $(0.001)$ \\
\hline Fixed Effects & Y & $\mathrm{Y}$ & $\mathrm{Y}$ & Y & $\mathrm{Y}$ & $\mathrm{Y}$ \\
\hline $\mathrm{N}$ & 3517 & 3517 & 3517 & 3517 & 3517 & 3517 \\
\hline Adjusted $\mathrm{R}^{2}$ & 0.169 & 0.173 & 0.271 & 0.265 & 0.146 & 0.145 \\
\hline
\end{tabular}

FE, ordinary least squares with fixed effects. Life Satisfaction takes a value of $1=$ Very Dissatisfied, $7=$ Very Satisfied. Control variables included as in table 4. Cluster-robust standard errors at the village level are in parentheses. ${ }^{*} p<0.1,{ }^{* *} p<0.05,{ }^{* * *} p<0.01$ 


\section{Appendices - For Online Publication}

The Following Appendices are displayed in three parts. Appendix A presents a series of Maps and Charts references in the Main text. Appendix B presents the full regression tables referred to in the main results table. Appendix $\mathrm{C}$ presents a series of mechanical robustness tests that demonstrate the validity of our results to alternative specifications and outliers.

\section{Appendix A - Maps, and Graphs}

Appendix A presents a series of graphs and maps that have been referenced to in section 2 of the main text. It also provides the complete table of descriptive statistics referred to in the data description.

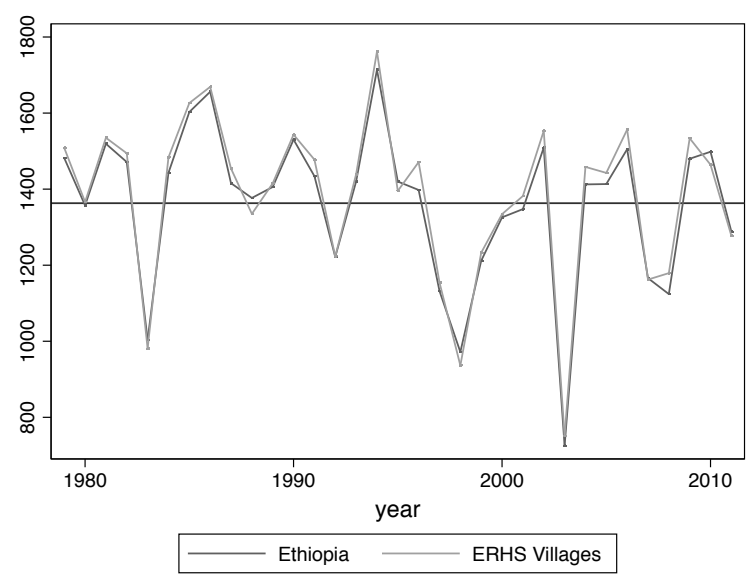

Figure 1: Differences in the average annual rainfall of the villages and Ethiopia as a whole. 


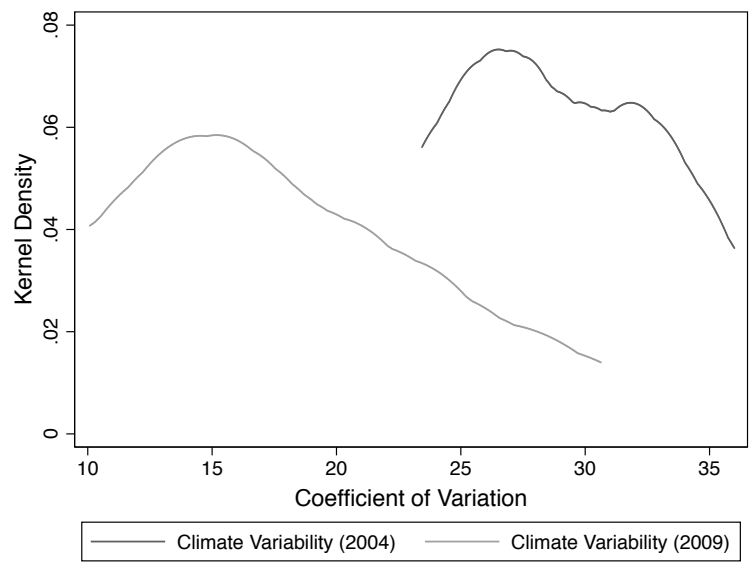

Figure 2: Differences in the Coefficient of Variation across villages between the two time periods.
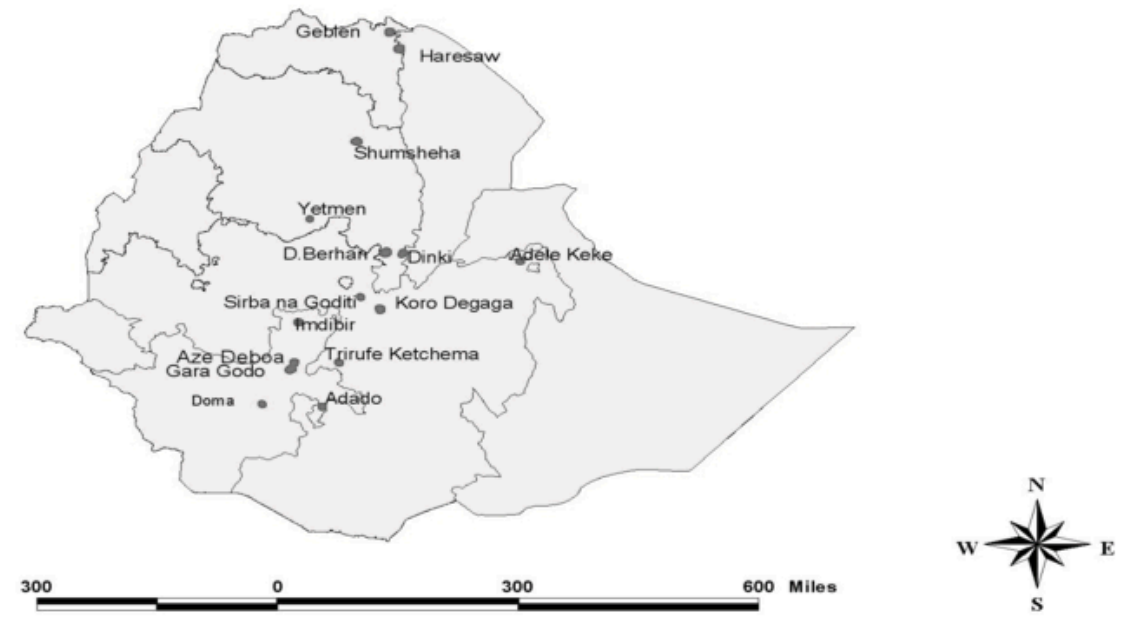

Figure 3: The ERHS Villages (Dercon \& Hoddinott, 2009) 


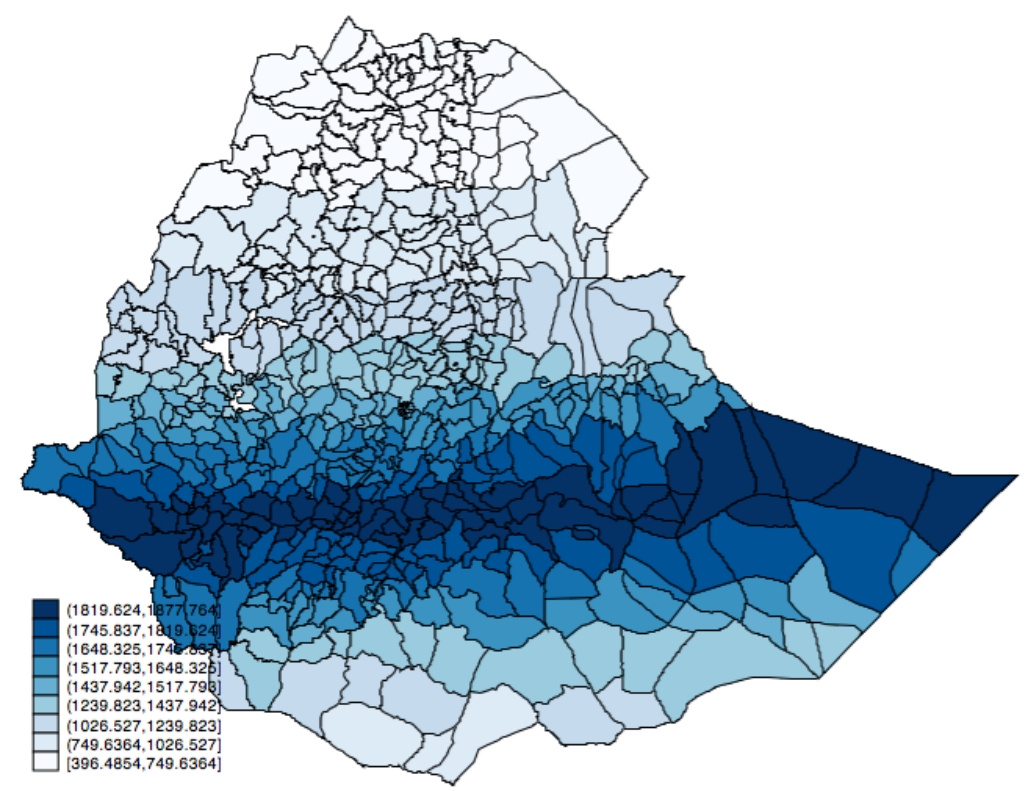

Figure 4: Average Annual Rainfall (1979-2011)

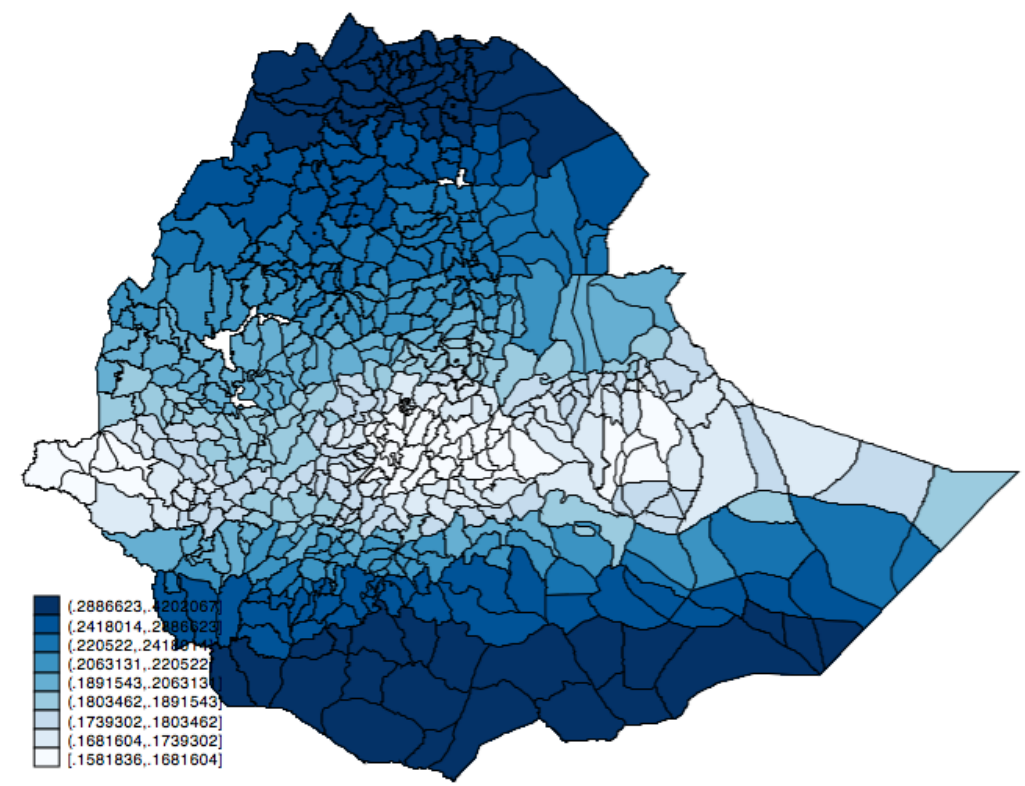

Figure 5: The Coefficient of Variation (1979-2011) 
Table A1: Summary statistics - Ethiopian Rural Household Survey

\begin{tabular}{|c|c|c|c|c|c|c|c|}
\hline Variable & Mean & Std. Dev. & $\mathrm{N}$ & Mean & Std. Dev. & $\mathrm{N}$ & \\
\hline Dependent Variables & & & & Muslim & 0.24 & 0.427 & 3781 \\
\hline Reported Life Satisfaction & 3.97 & 1.70 & 3877 & Other & 0.016 & 0.125 & 3781 \\
\hline Cantril Ladder & 4.47 & 1.81 & 3866 & No Schooling & 0.563 & 0.496 & 3877 \\
\hline Reported Happiness & 1.86 & 0.645 & 3869 & Grades 1-7 & 0.207 & 0.405 & 3877 \\
\hline Climate Variables & & & & Grades 8 plus & 0.049 & 0.216 & 3877 \\
\hline Climate Variability (Annual) & 22.98 & 7.71 & 3877 & Illness & 0.249 & 0.432 & 3796 \\
\hline Climate Variability (Belg) & 36.29 & 11.78 & 3877 & Household variables & & & \\
\hline Climate Variability (Kiremt) & 23.17 & 10.34 & 3877 & Richest & 0.011 & 0.104 & 3869 \\
\hline Rainfall Shock (Past 5 years) & 0.712 & 0.45245 & 3877 & Richer than Most & 0.123 & 0.3288 & 3869 \\
\hline Log Annual Std. Dev. Rainfall (mm) & 5.90 & 0.479 & 3877 & Average* & 0.516 & 0.49 & 3869 \\
\hline Rainfall (mm) (Day of Survey) & 3.42 & 4.65 & 3877 & Poorer than Most & 0.456 & 0.384 & 3869 \\
\hline Average Daily Temperature (Day of Survey) & 26.65 & 0.829 & 3877 & Poorest & 0.053 & 0.225 & 3869 \\
\hline Respondent variables & & & & Richer than three years ago & 0.469 & 0.499 & 3849 \\
\hline Age & 46.612 & 15.203 & 3774 & Poorer than three years ago & 0.236 & 0.425 & 3849 \\
\hline Female & 0.41 & 0.49 & 3877 & No change in income compared to three years ago* & 0.293 & 0.455 & 3849 \\
\hline Unemployed & 0.016 & 0.126 & 3877 & Larger social network & 0.271 & 0.444 & 3795 \\
\hline Married* & 0.764 & 0.425 & 3773 & Smaller social network & 0.277 & 0.447 & 3795 \\
\hline Single & 0.045 & 0.208 & 3773 & Smaller social network & 0.277 & 0.447 & 3795 \\
\hline Divorced & 0.045 & 0.207 & 3773 & No change in social network* & 0.451 & 0.497 & 3795 \\
\hline Widowed & 0.146 & 0.353 & 3773 & Livestock & 2.844 & 3.079 & 3854 \\
\hline Not Religious* & 0.002 & 0.043 & 3781 & Log Real Consumption per capita & 3.973 & 0.776 & 3873 \\
\hline Christian & 0.742 & 0.437 & 3781 & Log Household Size & 1.676 & 0.507 & 3873 \\
\hline
\end{tabular}

* denotes reference group. 


\section{Appendix B - Main Results}

Appendix B provides the complete regression tables for the main analysis referred to in section 3. Table 1 provides the main results. Table 2 provides the marginal effects for the ordered probit specification.

Table A1: Life Satisfaction Regressions: Main Results

\begin{tabular}{lccc}
\hline & $(1)$ & $(2)$ & $(3)$ \\
Dependent Variable: Life Satisfaction & OPROBIT-RE & $\mathrm{RE}$ & $\mathrm{FE}$ \\
\hline Core variable & & & \\
CV & $-0.047^{* * *}$ & $-0.077^{* *}$ & $-0.070^{* *}$ \\
Negative Rainfall Shock (past 5 years) & $(0.013)$ & $(0.031)$ & $(0.030)$ \\
& -0.115 & -0.140 & -0.272 \\
Average Temperature (Day of Survey) & $(0.081)$ & $(0.295)$ & $(0.307)$ \\
& 0.030 & 0.091 & 0.313 \\
Rainfall (mm) (Day of Survey) & $(0.070)$ & $(0.165)$ & $(0.208)$ \\
Individual Characteristics & -0.001 & -0.003 & -0.014 \\
Age & $(0.002)$ & $(0.006)$ & $(0.009)$ \\
Age squared & & & \\
Female & $-0.026^{* * *}$ & $-0.033^{* * *}$ & $-0.046^{* *}$ \\
Single & $(0.007)$ & $(0.012)$ & $(0.020)$ \\
Divorced & $0.000^{* * *}$ & $0.000^{* * *}$ & $0.000^{* * *}$ \\
& $(0.000)$ & $(0.000)$ & $(0.000)$ \\
& 0.004 & 0.013 & - \\
& $(0.040)$ & $(0.063)$ & - \\
& $-0.310^{* *}$ & $-0.414^{* *}$ & $-0.804^{*}$ \\
& $(0.154)$ & $(0.185)$ & $(0.407)$ \\
& $-0.237^{* *}$ & $-0.338^{* * *}$ & $-0.553^{*}$ \\
& $(0.098)$ & $(0.122)$ & $(0.277)$ \\
& 0.050 & 0.109 & -0.060 \\
\hline
\end{tabular}


Table A1 - continued from previous page

\begin{tabular}{lccc}
\hline & $(1)$ & $(2)$ & $(3)$ \\
& OPROBIT-RE & RE & FE \\
\hline \multirow{2}{*}{ Widowed } & $(0.095)$ & $(0.120)$ & $(0.350)$ \\
Christian & -0.009 & 0.014 & 0.066 \\
& $(0.059)$ & $(0.104)$ & $(0.199)$ \\
Muslim & $1.221^{* *}$ & $1.339^{* * *}$ & - \\
& $(0.496)$ & $(0.233)$ & - \\
Other & $1.106^{* *}$ & $1.179^{* * *}$ & - \\
& $(0.500)$ & $(0.260)$ & - \\
Grades 1-7 & $1.502^{* * *}$ & $1.784^{* * *}$ & - \\
Grades 8 plus & $(0.514)$ & $(0.356)$ & - \\
Illness & -0.071 & $-0.111^{* *}$ & -0.042 \\
& $(0.049)$ & $(0.051)$ & $(0.157)$ \\
Household Characteristics & $-0.310^{* * *}$ & $-0.498^{* * *}$ & -0.537 \\
Richest & $(0.090)$ & $(0.151)$ & $(0.303)$ \\
Richer than most & -0.048 & -0.056 & -0.032 \\
Poorer than Most & $(0.043)$ & $(0.090)$ & $(0.099)$ \\
Poorest & & & \\
& $0.295^{*}$ & 0.233 & 0.111 \\
& $(0.173)$ & $(0.399)$ & $(0.705)$ \\
& $0.377^{* * *}$ & $0.540^{* * *}$ & $0.315^{* *}$ \\
& $(0.059)$ & $(0.098)$ & $(0.147)$ \\
& $-0.567^{* * *}$ & $-0.871^{* * *}$ & $-0.792^{* * *}$ \\
& $(0.046)$ & $(0.086)$ & $(0.147)$ \\
& $-1.062^{* * *}$ & $-1.452^{* * *}$ & $-1.430^{* * *}$ \\
& $(0.095)$ & $(0.101)$ & $(0.208)$ \\
& $0.097^{* *}$ & 0.139 & -0.003 \\
& $(0.043)$ & $(0.103)$ & $(0.156)$ \\
& $-0.213^{* * *}$ & $-0.336^{* * *}$ & $-0.410^{* *}$ \\
\hline
\end{tabular}

Continued on next page 
Table A1 - continued from previous page

\begin{tabular}{lccc}
\hline & $(1)$ & $(2)$ & $(3)$ \\
& OPROBIT-RE & RE & FE \\
\hline \multirow{3}{*}{ Increased Social Network } & $(0.052)$ & $(0.094)$ & $(0.142)$ \\
& 0.052 & 0.058 & 0.018 \\
Decreased Social Network & $(0.044)$ & $(0.097)$ & 0.156 \\
& $-0.082^{*}$ & -0.117 & $-0.364^{* * *}$ \\
Livestock & $(0.045)$ & $(0.074)$ & $(0.142)$ \\
& $0.015^{* * *}$ & 0.017 & 0.020 \\
Log Real Consumption per capita & $(0.005)$ & $(0.059)$ & $(0.017)$ \\
& $0.220^{* * *}$ & $0.300^{* * *}$ & $0.373^{* * *}$ \\
Log Household Size & $(0.031)$ & $(0.059)$ & $(0.109)$ \\
& $0.090^{*}$ & 0.114 & 0.114 \\
Year Dummies & $(0.048)$ & $(0.112)$ & $(0.215)$ \\
Month Dummies & YES & YES & YES \\
Village Dummies & YES & YES & YES \\
Individual Fixed-Effects & YES & YES & - \\
\hline Observations & NO & NO & YES \\
Log-likelihood & 3,517 & 3,517 & 3,517 \\
$\mathrm{R}^{2}$ & -5710.6275 & - & - \\
\hline \hline
\end{tabular}

${ }^{\text {a }}$ OPROBIT-RE, ordered probit with random effects; RE, generalised least squares with random effects; FE, ordinary least squares with fixed effects. Life Satisfaction takes a value of $1=$ Very Dissatisfied, $7=$ Very Satisfied.

${ }^{\mathrm{b}}$ Cluster-robust standard errors at the village level are in parentheses.

c* $p<0.1,{ }^{* *} p<0.05,{ }^{* * *} p<0.01$ 
Table A2: Marginal Effects: Computed from Table A2, Column 1

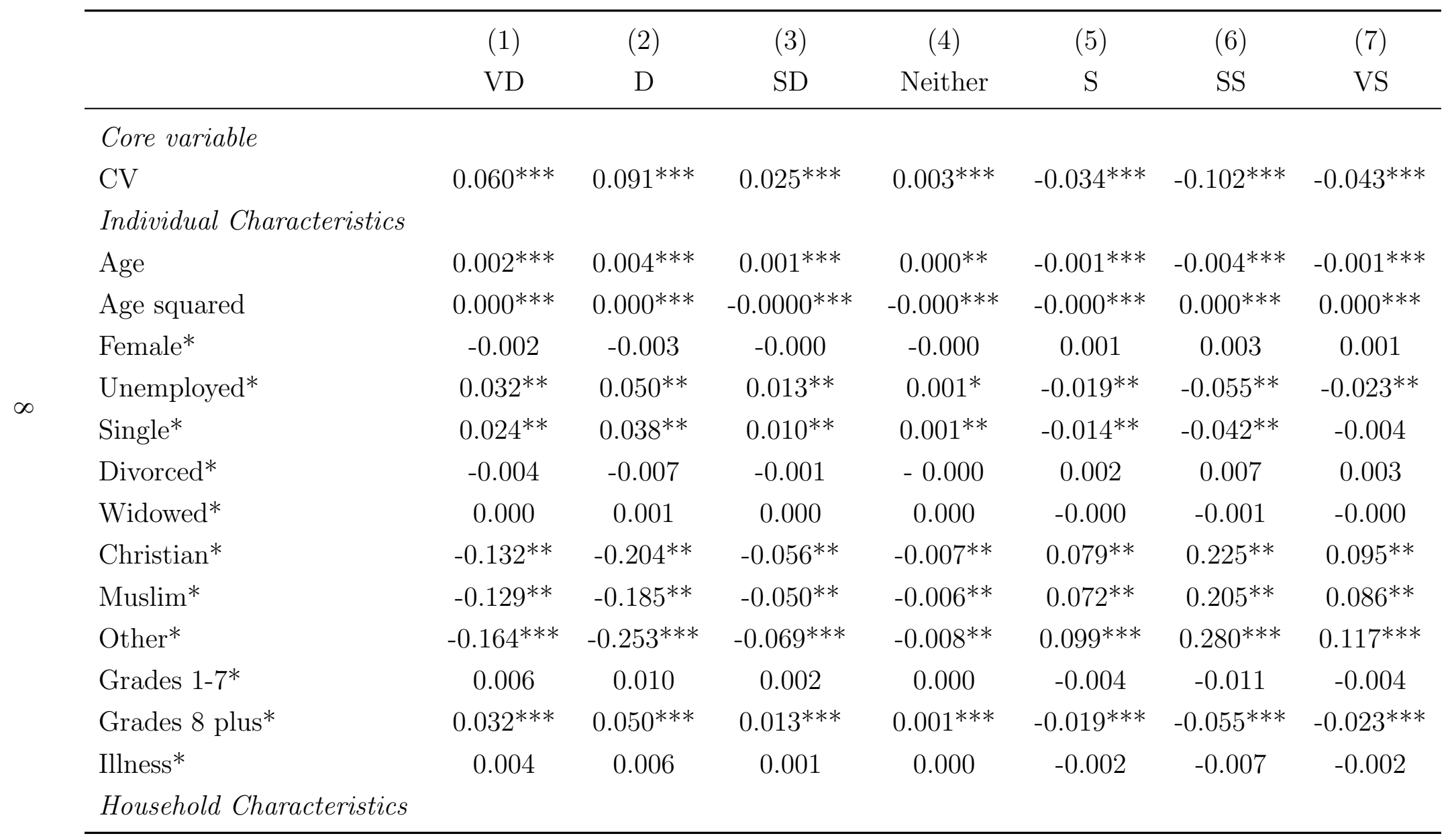


Table A2 - continued from previous page

\begin{tabular}{|c|c|c|c|c|c|c|c|}
\hline & (1) & $(2)$ & (3) & (4) & (5) & (6) & (7) \\
\hline & VD & $\mathrm{D}$ & SD & Neither & S & SS & VS \\
\hline Richest* & $-0.031^{*}$ & $-0.048^{*}$ & $-0.013^{*}$ & -0.001 & $0.018^{*}$ & $0.053^{*}$ & $0.022^{*}$ \\
\hline Richer than Most* & $-0.041^{* * *}$ & $-0.063^{* * *}$ & $-0.002^{* * *}$ & $-0.0021^{* * *}$ & $0.024^{* * *}$ & $0.069^{* * *}$ & $0.029^{* * *}$ \\
\hline Poorer than Most* & $0.061^{* * *}$ & $0.094^{* * *}$ & $0.025^{* * *}$ & $0.003^{* * *}$ & $-0.036^{* * *}$ & $-0.103^{* * *}$ & $-0.043^{* * *}$ \\
\hline Poorest* & $0.116^{* * *}$ & $0.179^{* * *}$ & $0.049^{* * *}$ & $0.006^{* * *}$ & $-0.069^{* *}$ & $-0.197^{* * *}$ & $-0.083^{* * *}$ \\
\hline Richer than 3 years ago* & $-0.010^{* *}$ & $-0.016^{* *}$ & $-0.004^{* *}$ & $-0.000^{* *}$ & $0.006^{* *}$ & $0.017^{* *}$ & $0.007^{* *}$ \\
\hline Poorer than 3 years ago* & $0.023^{* * *}$ & $0.021^{* * *}$ & $0.009^{* * *}$ & $0.001^{* * *}$ & $-0.014^{* * *}$ & $-0.039 * * *$ & $-0.016 * * *$ \\
\hline Increased Social Network* & -0.004 & -0.006 & -0.001 & -0.000 & 0.002 & 0.007 & 0.003 \\
\hline Decreased Social Network* & $0.009^{* *}$ & $0.014^{* *}$ & $0.004^{* *}$ & $0.000^{*}$ & $-0.005^{* *}$ & $-0.016^{* *}$ & $-0.006^{* *}$ \\
\hline Livestock & -0.001 & $-0.002^{* * *}$ & $-0.000^{* * *}$ & $-0.000^{* * *}$ & $0.001^{* * *}$ & $0.003^{* * *}$ & $0.001^{* * *}$ \\
\hline \multicolumn{8}{|l|}{ Log Real Consumption } \\
\hline per capita & $-0.020^{* * *}$ & $-0.031^{* * *}$ & $-0.008^{* * *}$ & $-0.001^{* * *}$ & $0.012^{* * *}$ & $0.034^{* * *}$ & $0.014^{* * *}$ \\
\hline Log Household Size & -0.008 & -0.012 & -0.003 & -0.000 & 0.004 & 0.013 & 0.005 \\
\hline
\end{tabular}

$* * * \mathrm{p}<0.01,{ }^{* *} \mathrm{p}<0.05,{ }^{*} \mathrm{p}<0.1$ 


\section{Appendix C - Robustness tests}

Appendix $\mathrm{C}$ presents additional robustness tests referred to in section 4 .

Table A1: Changes to the Temporal Measurement of Climate Variability

\begin{tabular}{|c|c|c|c|}
\hline & $\begin{array}{c}\text { (1) } \\
\text { Annual }\end{array}$ & $\begin{array}{c}(2) \\
\text { Belg }\end{array}$ & $\begin{array}{c}(3) \\
\text { Kiremt }\end{array}$ \\
\hline Climate Variability (10 years) & $\begin{array}{l}-0.0642 \\
(0.0521)\end{array}$ & $\begin{array}{c}-0.0293^{* * *} \\
(0.0062)\end{array}$ & $\begin{array}{l}-0.0205 \\
(0.0222)\end{array}$ \\
\hline Climate Variability (9 years) & $\begin{array}{l}-0.0550 \\
(0.0419)\end{array}$ & $\begin{array}{c}-0.0208^{* * *} \\
(0.0068)\end{array}$ & $\begin{array}{l}-0.0352 \\
(0.0228)\end{array}$ \\
\hline Climate Variability (8 years) & $\begin{array}{c}-0.615^{* *} \\
(0.0274)\end{array}$ & $\begin{array}{c}-0.0222^{* * *} \\
(0.0059)\end{array}$ & $\begin{array}{c}-0.0398^{* *} \\
(0.0134)\end{array}$ \\
\hline Climate Variability (7 years) & $\begin{array}{l}-0.0580 \\
(0.0247)\end{array}$ & $\begin{array}{c}-0.0230 * * * \\
(0.0047)\end{array}$ & $\begin{array}{c}-0.0278^{* *} \\
(0.0176)\end{array}$ \\
\hline Climate Variability (6 years) & $\begin{array}{l}-0.0580 \\
(0.0366)\end{array}$ & $\begin{array}{c}-0.0230 * * * \\
(0.0065)\end{array}$ & $\begin{array}{c}-0.0278^{* *} \\
(0.0127)\end{array}$ \\
\hline Climate Variability (5 years) & $\begin{array}{c}-0.0700 * * \\
(0.0297)\end{array}$ & $\begin{array}{c}-0.0234^{* * *} \\
(0.0063)\end{array}$ & $\begin{array}{l}-0.0171 \\
(0.0098)\end{array}$ \\
\hline Climate Variability (4 years) & $\begin{array}{c}-0.0481^{* *} \\
(0.0217)\end{array}$ & $\begin{array}{c}-0.0149 * \\
(0.0080)\end{array}$ & $\begin{array}{l}-0.0182^{*} \\
(0.0098)\end{array}$ \\
\hline Climate Variability (3 years) & $\begin{array}{l}-0.0166 \\
(0.0144)\end{array}$ & $\begin{array}{l}0.0195 * \\
(0.0095)\end{array}$ & $\begin{array}{c}-0.0087^{*} \\
(0.0047)\end{array}$ \\
\hline Climate Variability (2 years) & $\begin{array}{l}-0.0087 \\
(0.0108)\end{array}$ & $\begin{array}{c}0.0144 \\
(0.0125)\end{array}$ & $\begin{array}{l}-0.0058^{*} \\
(0.0031)\end{array}$ \\
\hline $\begin{array}{l}\text { Month Dummies } \\
\text { Year Dummies } \\
\text { Individual Fixed Effects }\end{array}$ & $\begin{array}{l}\text { Yes } \\
\text { Yes } \\
\text { Yes }\end{array}$ & $\begin{array}{l}\text { Yes } \\
\text { Yes } \\
\text { Yes }\end{array}$ & $\begin{array}{l}\text { Yes } \\
\text { Yes } \\
\text { Yes }\end{array}$ \\
\hline $\begin{array}{l}\text { Observations } \\
\text { Adjusted } \mathrm{R}^{2}\end{array}$ & $\begin{array}{c}3,610 \\
{[0.153-0.166]}\end{array}$ & $\begin{array}{c}3,610 \\
{[0.162-0.173]}\end{array}$ & $\begin{array}{c}3,610 \\
{[0.153-0.166]}\end{array}$ \\
\hline $\begin{array}{l}{ }^{\mathrm{a}} \mathrm{FE} \text {, ordinary least squares wit } \\
\text { Very Dissatisfied, } 7=\text { Very Sati } \\
{ }^{\mathrm{b}} \text { Cluster-robust standard errors } \\
{ }^{\mathrm{c}} \text { For each different measure we } \\
\text { over the same period. After } 5 \mathrm{y} \\
\text { controlled for whether a shock } \\
\mathrm{d} \text { The range of the Adjusted } \mathrm{R}^{2} \\
\text { e }{ }^{*} p<0.1,{ }^{* *} p<0.05,{ }^{* * *} p<\end{array}$ & $\begin{array}{l}\text { fixed effects. Li } \\
\text { ied. Control var } \\
\text { the village lev } \\
\text { ontrol for wheth } \\
\text { ars, all villages } \\
\text { s experienced in } \\
\text { reported. } \\
.01\end{array}$ & $\begin{array}{l}\text { Satisfaction } t \\
\text { les included } \\
\text { are in parentl } \\
\text { a rainfall sho } \\
\text { experienced } \\
\text { e previous } 5\end{array}$ & $\begin{array}{l}\text { es a value of } 1= \\
\text { in table } 4 . \\
\text { es. } \\
\text { was experienced } \\
\text { shock and so we } \\
\text { ars. }\end{array}$ \\
\hline
\end{tabular}

Table A1 demonstrates the robustness of our results to alternative time periods over which we measure the coefficient of variation. Most importantly, we observe that our measure of Climate Variability over the Belg season is 
significant over most alternative time periods. Given the small number of villages and rounds of data, one of the major limitations of this study is the amount of spatial and temporal variation we are able to identify an effect from. As we extend the number of time periods over which we measure the coefficient of variation, this is likely to reduce the variation through time as well, reducing the signal that we are able to capture. Similarly, as we reduce the number of years over which we measure the coefficient of variation, we are less likely to distinguish between climate and weather. In addition to the controls displayed in the table, we control for whether the village experienced a weather shock in the previous $x$ years, in which $x$ is equal to the time scale over which we measure the coefficient of variation, ranging from 2 years up to 10 years. Unfortunately, each village in our sample had experienced at least one shock after 5 years and so we held the variable fixed at 5 years for time scales above 5 years.

Table A2: Climate Variability and Life Satisfaction - Removal of Outliers.

\begin{tabular}{lccc}
\hline Dependent Variable: Life Satisfaction & Geblen Removed & Korodegaga Removed & Both Removed \\
\hline Belg Climate & $-0.017^{* *}$ & $-0.023^{* * *}$ & $-0.015^{*}$ \\
Variability & $(0.007)$ & $(0.006)$ & $(0.007)$ \\
Negative Rainfall Shock & 0.075 & 0.232 & 0.238 \\
(past 5 years) & $(0.325)$ & $(0.312)$ & $(0.312)$ \\
Average Temperature & 0.280 & $0.390^{*}$ & $0.407^{* *}$ \\
(Day of Survey) & $(0.193)$ & $(0.187)$ & $(0.164)$ \\
Rainfall (mm) & -0.006 & -0.007 & -0.006 \\
(Day of Survey) & $(0.004)$ & $(0.004)$ & $(0.004)$ \\
\hline Month dummies & $\mathrm{Y}$ & $\mathrm{Y}$ & $\mathrm{Y}$ \\
Year dummies & $\mathrm{Y}$ & $\mathrm{Y}$ & $\mathrm{Y}$ \\
Individual fixed effects & $\mathrm{Y}$ & 3,288 & 3,122 \\
\hline $\mathrm{N}$ & 3,351 & 0.179 & 0.170 \\
Adjusted $\mathrm{R}^{2}$ & 0.169 & & \\
\hline a FE, ordinary least squares with fixed effects. Life Satisfaction takes a value of $1=$ Very Dissatisfied, \\
$7=$ Very Satisfied. Control variables included as in table 3. \\
b Cluster-robust standard errors at the village level are in parentheses. \\
c $*<0.1, * * p<0.05, * * *<0.01$
\end{tabular}

Table A2 demonstrates the robustness of our results to the removal of 
outliers in the explanatory variable. We begin by dropping the village with the highest climate variability, Geblen. In the next test, we drop the village with the lowest climate variability, Korodegaga. In the final test, we drop both villages. The fact that these results remain significant once we have removed so much of the variation emphasises the importance and magnitude of the effect.

Table A3 shows how our results are robust to an alternative specification of our explanatory variable, which we define as the standard deviation of rainfall over each period: 2000-2004, and 2005-2009.

Table A3: Climate Variability and Life Satisfaction - Alternative Explanatory Variable.

\begin{tabular}{lcc}
\hline Dependent Variable: Life Satisfaction & FE & FE \\
\hline Annual Climate Variability (log of std. dev) & $\begin{array}{c}-1.222^{* *} \\
(0.517)\end{array}$ & \\
Belg Climate Variability (log of std. dev) & & $-0.934^{* * *}$ \\
& & $(0.031)$ \\
Negative Rainfall Shock (past 5 years) & -0.326 & 0.131 \\
& $(0.282)$ & $(0.295)$ \\
Average Temperature (Day of Survey) & $0.496^{* *}$ & 0.309 \\
& $(0.214)$ & $(0.196)$ \\
Rainfall (mm) (Day of Survey) & -0.006 & -0.006 \\
& $(0.004)$ & $(0.004)$ \\
\hline Month dummies & $\mathrm{Y}$ & $\mathrm{Y}$ \\
Year dummies & $\mathrm{Y}$ & $\mathrm{Y}$ \\
Individual fixed effects & $\mathrm{Y}$ & $\mathrm{Y}$ \\
\hline $\mathrm{N}$ & 3,610 & 3,610 \\
Adjusted R & 0.175 & 0.178 \\
\hline
\end{tabular}

${ }^{a}$ FE, ordinary least squares with fixed effects. Life Satisfaction takes a value of $1=$ Very Dissatisfied, $7=$ Very Satisfied. Control variables include gender, age, age-squared, log of real household consumption per capita, log of livestock owned (tropical livestock units), number of household members, dummies for marital status, unemployment, education, illness experienced in the previous 4 weeks, social network changes, relative income, household standing relative to 3 years ago.

b Cluster-robust standard errors at the village level are in parentheses.

c * $p<0.1,{ }^{* *} p<0.05,{ }^{* * *} p<0.01$

We observe surprisingly similar effects in terms of magnitude to our orig- 
inal measure of climate variability. As with our standard measure of climate variability, the coefficient of variation, a one standard deviation increase in the standard deviation of rainfall (0.479) results in a decrease in life satisfaction equivalent to a two percent decline in real consumption per capita.

Table A4: Climate Variability and SWB: Results from Alternative Models with Village Fixed Effects.

\begin{tabular}{lccc}
\hline Dependent Variable: Life Satisfaction & OPROBIT- RE & RE & FE \\
\hline Climate Variability & $-0.050^{* * *}$ & $-0.059^{* * *}$ & $-0.079^{* *}$ \\
Negative Rainfall Shock (past 5 years) & $(0.006)$ & $(0.011)$ & $(0.030)$ \\
& -0.040 & 0.209 & -0.139 \\
Average Temperature (Day of Survey) & $(0.062)$ & $(0.207)$ & $(0.291)$ \\
& $-0.069^{*}$ & $-0.171^{*}$ & 0.088 \\
Rainfall (mm) (Day of Survey) & $(0.037)$ & $(0.089)$ & $(0.158)$ \\
& -0.003 & -0.003 & -0.004 \\
\hline Month dummies & $(0.004)$ & $(0.006)$ & $(0.006)$ \\
Year dummies & $\mathrm{Y}$ & $\mathrm{Y}$ & $\mathrm{Y}$ \\
Village Fixed Effects & $\mathrm{Y}$ & $\mathrm{Y}$ & $\mathrm{Y}$ \\
\hline N & $\mathrm{N}$ & $\mathrm{N}$ & $\mathrm{Y}$ \\
Log-likelihood & 3,461 & 3,461 & 3,461 \\
Adjusted R & $-5,649.0032$ & - & - \\
\hline
\end{tabular}

${ }^{\text {a }}$ OPROBIT-RE, ordered probit with random effects; RE, generalised least squares with random effects; FE, ordinary least squares with fixed effects. Life Satisfaction takes a value of $1=$ Very Dissatisfied, 7 $=$ Very Satisfied. Control variables include gender, age, age-squared, log of real household consumption per capita, log of livestock owned (tropical livestock units), number of household members, dummies for marital status, unemployment, education, illness experienced in the previous 4 weeks, social network changes, relative income, household standing relative to 3 years ago.

b Cluster-robust standard errors at the village level are in parentheses.

c $* p<0.1,{ }^{* *} p<0.05, * * * p<0.01$

Table A4 demonstrates the robustness of our results to village fixed effects. As we observe there is very little change in the magnitude of the coefficients when we control for these factors. 
Table A5: Climate Variability and SWB: Results from Alternative Models with Contemporaneous Weather Shock Controls.

\begin{tabular}{lccc}
\hline $\begin{array}{l}\text { Dependent Variable: } \\
\text { Life Satisfaction }\end{array}$ & OPROBIT- RE & $\mathrm{RE}$ & $\mathrm{FE}$ \\
\hline Climate & $-0.049^{* * *}$ & $-0.079^{* * *}$ & $-0.073^{* *}$ \\
Variability & $(0.012)$ & $(0.030)$ & $(0.003)$ \\
Negative Rainfall Shock & $-0.135^{*}$ & -0.160 & -0.276 \\
(Last Agricultural Year) & $(0.062)$ & $(0.298)$ & $(0.302)$ \\
Average Temperature & 0.025 & 0.083 & 0.315 \\
(Day of Survey) & $(0.071)$ & $(0.006)$ & $(0.224)$ \\
Rainfall (mm) & -0.003 & -0.003 & -0.016 \\
(Day of Survey) & $(0.004)$ & $(0.006)$ & $(0.009)$ \\
\hline Month dummies & $\mathrm{Y}$ & $\mathrm{Y}$ & $\mathrm{Y}$ \\
Year dummies & $\mathrm{Y}$ & $\mathrm{Y}$ & $\mathrm{Y}$ \\
Village Dummies & $\mathrm{Y}$ & $\mathrm{Y}$ & - \\
Individual Fixed Effects & $\mathrm{N}$ & $\mathrm{N}$ & $\mathrm{Y}$ \\
\hline N & 3,461 & 3,461 & 3,461 \\
Log-likelihood & $-5,623.6164$ & - & - \\
Adjusted R & - & 0.153 & 0.169 \\
\hline
\end{tabular}

a OPROBIT-RE, ordered probit with random effects; RE, generalised least squares with random effects; FE, ordinary least squares with fixed effects. Life Satisfaction takes a value of $1=$ Very Dissatisfied, $7=$ Very Satisfied. Control variables include gender, age, age-squared, log of real household consumption per capita, log of livestock owned (tropical livestock units), number of household members, dummies for marital status, unemployment, education, illness experienced in the previous 4 weeks, social network changes, relative income, household standing relative to 3 years ago.

b Cluster-robust standard errors at the village level are in parentheses.

c $* p<0.1,{ }^{* *} p<0.05,{ }^{* * *} p<0.01$

Table A5 shows that controlling for the negative rainfall shocks in the most recent agricultural has no qualitative effect, and only a minor quantitative impact on our results. 